\title{
Favipiravir and Ivermectin Showed in Vitro \\ Synergistic Antiviral Activity against SARS-CoV-2
}

\section{Kunlakanya Jitobaom}

Siriraj Hospital

Chompunuch Boonarkart

Siriraj Hospital

\section{Suwimon Manopwisedjaroen}

Mahidol University

Nuntaya Punyadee

Siriraj Hospital

\section{Suparerk Borwornpinyo}

Mahidol University

Arunee Thitithanyanont

Mahidol University

Panisadee Avirutnan

Siriraj Hospital

Prasert Auewarakul ( $\sim$ prasert.aue@mahidol.ac.th )

Siriraj Hospital

\section{Research Article}

Keywords: SARS-CoV-2, Favipiravir, Ivermectin, anti-parasitic drugs, repurposed drugs, drug combination

Posted Date: October 14th, 2021

DOI: https://doi.org/10.21203/rs.3.rs-941811/v1

License: (c) (1) This work is licensed under a Creative Commons Attribution 4.0 International License.

Read Full License 


\section{Abstract}

Despite the urgent need for effective antivirals against SARS-CoV-2 to mitigate the catastrophic impact of the COVID-19 pandemic, there are still no proven effective and widely available antivirals for COVID-19 treatment. Favipiravir and Ivermectin are among common repurposed drugs, which have been provisionally used in some countries. There have been clinical trials with mixed results, and therefore, it is still inconclusive whether they are effective or should be dismissed. It is plausible that the lack of clearcut clinical benefits was due to the finding of only marginal levels of in vivo antiviral activity. An obvious way to improve the activity of antivirals is to use them in synergistic combinations. Here we show that Favipiravir and Ivermectin had the synergistic effects against SARS-CoV-2 in Vero cells. The combination may provide better efficacy in COVID-19 treatment. In addition, we found that Favipiravir had an additive effect with Niclosamide, another repurposed anti-parasitic drug with anti-SARS-CoV-2 activity. However, the anti-SARS-CoV-2 activity of Favipiravir was drastically reduced when tested in Calu-3 cells. This suggested that this cell type might not be able to metabolize Favipiravir into its active form, and that this deficiency in some cell types may affect in vivo efficacy of this drug.

\section{Introduction}

Up to the end of August 2021, the COVID-19 pandemic has resulted in more than 4.5 million deaths. The emergence of variants with antigenic changes causing vaccine escape has obliterated the hope to eradicate the virus, and the disease will likely continue to be a major problem for the foreseeable future. Effective antivirals are urgently needed to mitigate the disease burden, especially where vaccine supply is insufficient. In addition, infection and illnesses continue even in a vaccinated population, and effective antivirals would ensure the return to normalcy with further-reduced risk of severe disease and death. While new antivirals such as monoclonal antibodies have been developed, they are costly and not widely available. Furthermore, those monoclonal antibodies can be effectively used only in the early phase of the disease ${ }^{1}$. Repurposed drugs with antiviral activity have been the main target for developing COVID-19 treatments ${ }^{2}$. Remdesivir is the repurposed antiviral with the most supporting clinical data for its effectiveness and is recommended by many treatment guidelines ${ }^{3,4}$. However, the drug cannot be taken orally and therefore, is not used in mild cases or at an early phase. Early antiviral treatment is very likely to be more effective and will prevent not only death but also progression to severe disease ${ }^{5}$. Several repurposed drugs with in vitro antiviral activity have been tested in clinical trials ${ }^{2}$. Some have been shown to be ineffective, some showed mixed results. Marginal or low levels of efficacy could be a reason for the lack of clear-cut benefit for some of these drugs. Drug combination is a common approach to improve antiviral activity and efficacy, and has been successfully used for treatment of many viral diseases ${ }^{6}$. However, synergistic or at least an additive effect is needed to make a combination more effective than single drugs. We, therefore, tested combinations of common repurposed drugs with antiSARS-CoV-2 activity to guide further clinical development. 
Favipiravir was originally developed as an anti-influenza drug, and has been shown to have broad antiviral activity against viruses in many families ${ }^{7}$. It is metabolized intracellularly to its active form, Favipiravir-ribofuranosyl-5'-triphosphate ${ }^{8}$. It is believed to inhibit viral replication by inhibiting viral RNA polymerase and by inducing lethal hypermutations ${ }^{9,10}$. Favipiravir had been shown to have anti-SARSCoV-2 activity, and was tested in clinical trials with mixed results ${ }^{11}$. It is being used for COVID-19 treatment in some countries, including Thailand ${ }^{12}$.

Ivermectin is an anti-parasitic drug with broad antiviral and anti-SARS-CoV-2 activity ${ }^{13,14}$. Although many clinical trials have shown its efficacy in COVID-19 treatment and prophylaxis ${ }^{15}$, many others have indicated that it had no clinical benefit ${ }^{16}$. These trials varied in the dosages, time of initiating the treatment, and whether to take the drug with a meal. As earlier treatment is more likely to be effective and taking Ivermectin with a fatty meal was shown to increase absorption and drug plasma levels ${ }^{17}$. It is still possible that these factors might negatively influence trial outcomes, and the drug may provide some benefit in specific settings despite the disappointing clinical trial results. Chloroquine and Niclosamide are also repurposed drugs with anti-SARS-CoV-2 activity. While Chloroquine has been dismissed as ineffective by many ${ }^{18}$, Niclosamide is still an interesting drug that is being tested in clinical trials ${ }^{19}$. Regardless of these clinical trial results, these drugs are common repurposed drugs for COVID-19, which have relatively good safety profiles, are inexpensive and widely available. They should therefore be tested in combinations for in vitro synergistic activity, which may help identify combinations with good potential for further clinical testing.

\section{Results}

\section{Single drug treatment against SARS-CoV-2 in Vero E6 cells}

The main features of antiviral activities of Favipiravir, and the repurposed anti-parasitic drugs; Niclosamide, Ivermectin and Chloroquine are shown in Table 1 and Figure 1. Virus production was determined using both plaque assay and qRT-PCR and is expressed as the percent inhibition relative to the DMSO-treated cell control. The $\mathrm{IC}_{50}$ values determined by both methods are similar. The $\mathrm{IC}_{50}$ values calculated from the dose-response determined by qRT-PCR for Favipiravir, Ivermectin, Niclosamide and Chloroquine were $40.49,1.24,0.048$, and $0.89 \mu \mathrm{M}$, respectively. And the $\mathrm{IC}_{50}$ values calculated from the dose-response determined by plaque assay for Favipiravir, Ivermectin, Niclosamide and Chloroquine were $41.81,1.23,0.046$ and $0.82 \mu \mathrm{M}$, respectively. This confirmed that viral RNA quantitation could accurately determine the infectious viral output for these experiments, and for higher throughput, the qRT-PCR was used for screening of two-drug combinations. The selective indexes of each single drug treatment are also shown in Table 1. 
Table 1

The single drug treatment against SARS-CoV-2 in Vero E6 cells

\begin{tabular}{|c|c|c|c|c|c|c|}
\hline $\begin{array}{l}\text { Drug } \\
\text { candidates }\end{array}$ & $\begin{array}{l}\text { Drug } \\
\text { class }\end{array}$ & Drug indication & $\begin{array}{l}\mathrm{CC}_{50} \\
(\mu \mathrm{M})\end{array}$ & $\begin{array}{l}I_{50} \\
(\mu \mathrm{M}) \\
\text { qRT-PCR }\end{array}$ & $\begin{array}{l}\mathrm{IC}_{50} \\
(\mu \mathrm{M}) \\
\text { plaque } \\
\text { assay }\end{array}$ & $\begin{array}{l}\text { SI } \\
\left(\mathrm{CC}_{50} / \mathrm{IC}_{50}\right)\end{array}$ \\
\hline Favipiravir & $\begin{array}{l}\text { Direct } \\
\text { antiviral } \\
\text { agents }\end{array}$ & $\begin{array}{l}\text { Treatment of influenza, } \\
\text { and other viral infections. }\end{array}$ & 501.40 & 40.49 & 41.81 & 12.18 \\
\hline Ivermectin & $\begin{array}{l}\text { Anti- } \\
\text { parasitic } \\
\text { agents }\end{array}$ & $\begin{array}{l}\text { Treatment of } \\
\text { onchocerciasis, and other } \\
\text { worm infestations }\end{array}$ & 10.55 & 1.24 & 1.23 & 8.54 \\
\hline Niclosamide & $\begin{array}{l}\text { Anti- } \\
\text { parasitic } \\
\text { agents }\end{array}$ & $\begin{array}{l}\text { Treatment of tapeworm } \\
\text { and intestinal fluke } \\
\text { infections }\end{array}$ & 0.29 & 0.048 & 0.046 & 6.17 \\
\hline Chloroquine & $\begin{array}{l}\text { Anti- } \\
\text { malarial } \\
\text { agents }\end{array}$ & $\begin{array}{l}\text { Treatment of malaria, } \\
\text { rheumatic diseases and } \\
\text { Zika virus infection }\end{array}$ & 122.10 & 0.89 & 0.82 & 142.81 \\
\hline
\end{tabular}

The dose-response curves of a single drug treatment against SARS-CoV-2 are shown; (a) Favipiravir, (b) Ivermectin, (c) Niclosamide and (d) Chloroquine. Vero E6 cells were pre-treated with twofold serial dilutions of drug for $1 \mathrm{hr}$. and infected with SARS-CoV-2 at m.o.i. of 0.01. The infected cells were maintained in the medium containing serial dilutions of the single drugs or $0.5 \% \mathrm{DMSO}$ for two days. The virus production was determined using the plaque assay and qRT-PCR. The dose-response curves are expressed as the percent inhibition relative to the DMSO-treated cell control. The effect of drug treatment on the cell viability was determined using MTT assay and expressed relative to the DMSO-treated cell control.

\section{Two-drug Combination Treatment Against Sars-cov-2 In Vero E6 Cells}

The antiviral activities of Favipiravir and the repurposed anti-parasitic drugs combinations were assessed in vitro in order to find the combinations with good potential in COVID-19 treatment. Drug combinations were evaluated in Vero E6 cells including Favipiravir-Ivermectin, Favipiravir-Niclosamide, and FavipiravirChloroquine. The evaluations of two-drug combinations were performed following the same infection protocol by treating with 16 different pairwise combinations of two drugs.

\section{Favipiravir-ivermectin Combination}


The presence of Ivermectin induced a strong shift in the dose-response curves of Favipiravir, with 103.82, 48.78, 37.15 and 6.09-fold reduction of Favipiravir $\mathrm{IC}_{50}$ values in the presence of 2.4, 1.2, 0.6 and $0.3 \mu \mathrm{M}$ Ivermectin, respectively (Fig. 2a, Table 2). In a similar manner, the presence of Favipiravir also induced shift in Ivermectin dose-response curves with a 24.8-fold reduction of Ivermectin $I_{50}$ values in the presence of both 80 and $40 \mu \mathrm{M}$ of Favipiravir, while, the presence of 20 and $10 \mu \mathrm{M}$ of Favipiravir resulted in 12.4 and 4.28-fold reduction of Ivermectin $I_{50}$ values, respectively (Fig. 2b, Table 2). The doseresponse matrix shows a significant inhibitory effect in a large range of combinations (Fig. 2c). The calculated mean Loewe synergy score of 19.245 accounted for the synergistic effect between Favipiravir and Ivermectin, with the peak score of 33.053 (Fig. 2d). Moreover, the synergy score calculation using ZIP, HSA, and Bliss independence models gave values of 22.675, 30.249 and 22.741, respectively, which also indicated the synergy effect between Favipiravir and Ivermectin. All 16 pairwise combinations showed no significant cytotoxicity (Fig. 2a, b).

Vero cells were pre-treated for $1 \mathrm{hr}$. with twofold serial dilutions of Favipiravir in the presence of different fixed concentrations of Ivermectin (a) or alternatively, serial dilutions of Ivermectin in the presence of different fixed concentrations of Favipiravir (b). The cells were infected with SARS-CoV-2 at m.o.i. 0.01. After removing the virus inoculum, the cells were further maintained in the medium containing drugs for two days. Virus production was determined using qRT-PCR. The SynergyFinder was used to calculate the synergy score of two-drug combinations from different 16 pairwise combinations. The dose-response matrix (c) and the synergy map of two-drug combinations treatment (d) are shown. Areas with synergy score less than -10: the interaction between two drugs is likely to be antagonistic; from -10 to 10: the interaction between two drugs is likely to be additive; larger than 10: the interaction between two drugs is likely to be synergistic.

\section{Favipiravir-niclosamide Combination}

The presence of Niclosamide induced a shift in the dose-response curves of Favipiravir, with 33.19, 30.91, 4.76 and 5.15-fold reduction of Favipiravir $I_{50}$ values in the presence of $0.09,0.045,0.0255$ and 0.01125 $\mu \mathrm{M}$ Niclosamide, respectively (Fig. 3a, Table 2). Similarly, the presence of Favipiravir also induced shift in the Niclosamide dose-response curves, with 24, 12, 8 and 3.428-fold reduction of Niclosamide $I_{50}$ value in the presence of $80,40,20$ and $10 \mu \mathrm{M}$ of Favipiravir, respectively (Fig. 3b, Table 2). The dose-response matrix shows the increasing inhibitory effect due to the increasing concentrations of Favipiravir and Niclosamide (Fig. 3c). The mean Loewe synergy score of 9.61 accounted for the additive effect between Favipiravir and Niclosamide, with the peak score of 18.87 (Fig. 3d). The synergy scores of 12.43, 20.09 and 12.52 were obtained when using ZIP, HSA, and Bliss independence models, respectively which accounted for the synergy effect of Favipiravir and Niclosamide. All 16 pairwise combinations showed no significant cytotoxicity (Fig. 3a, b).

Vero cells were pre-treated for $1 \mathrm{hr}$. with twofold serial dilutions of Favipiravir in the presence of different fixed concentrations of Niclosamide (a) or alternatively, serial dilutions of Niclosamide in the presence of 
different fixed concentrations of Favipiravir (b). The cells were infected with SARS-CoV-2 at m.o.i. 0.01. After removing the virus inoculum, the cells were further maintained in the medium containing drugs for two days. Virus production was determined using qRT-PCR. The SynergyFinder was used to calculate the synergy score of two-drug combinations from different 16 pairwise combinations. The dose-response matrix (c) and the synergy map of two-drug combinations treatment (d) are shown. Areas with synergy score less than -10: the interaction between two drugs is likely to be antagonistic; from -10 to 10: the interaction between two drugs is likely to be additive; larger than 10: the interaction between two drugs is likely to be synergistic.

\section{Favipiravir-chloroquine Combination}

The results show that the presence of Chloroquine induced shift in the dose-response curves of Favipiravir, with $80.98,5.40,3.11$ and 1.72-fold reduction of Favipiravir $I C_{50}$ values in the presence of 1.7, $0.85,0.425$ and $0.2125 \mu \mathrm{M}$ Chloroquine, respectively (Fig. 4a, Table 2). The presence of Favipiravir also induced shift in the Chloroquine dose-response curves, with 44.5, 5.93, 5.56 and 1.48-fold reduction of Chloroquine $\mathrm{IC}_{50}$ value in the presence of $80,40,20$ and $10 \mu \mathrm{M}$ of Favipiravir, respectively (Fig. 4b, Table 2). The dose-response matrix shows the increasing inhibitory effect in the pairwise combinations with high concentrations of Favipiravir and Chloroquine (Fig. 4c). The synergy analysis shows the positive synergy score distributed with the high concentrations of both drugs, while the lower concentrations gave zero and negative synergy scores (Fig. 4d). The mean Loewe synergy score of -0.494 accounted for the additive effect between Favipiravir and Chloroquine, with the peak score of 11.189. The additive effect was shown to be driven by only Favipiravir and Chloroquine at high concentrations. The synergy scores of 0.609 and 0.242 were obtained when using ZIP, and Bliss independence models, which accounted for the additive effect of Favipiravir and Chloroquine. While using the HSA model, the synergy score of 10.064 indicated a small level of synergistic effect. All 16 pairwise combinations showed no significant cytotoxicity (Fig. 4a, b).

Vero cells were pre-treated for $1 \mathrm{hr}$. with twofold serial dilutions of Favipiravir in the presence of different fixed concentrations of Chloroquine (a) or alternatively, serial dilutions of Ivermectin in the presence of different fixed concentrations of Favipiravir (b). The cells were infected with SARS-CoV-2 at m.o.i. 0.01. After removing the virus inoculum, the cells were further maintained in the medium containing drugs for two days. The virus production was determined using qRT-PCR. The SynergyFinder was used to calculate the synergy score of two-drug combinations from different 16 pairwise combinations. The dose-response matrix (c) and the synergy map of two-drug combinations treatments (d) are shown. Areas with synergy score less than -10: the interaction between two drugs is likely to be antagonistic; from -10 to 10: the interaction between two drugs is likely to be additive; larger than 10: the interaction between two drugs is likely to be synergistic. 
Table 2

Antiviral activity of two-drug combination treatments against SARS-CoV-2 in Vero E6 cells

\begin{tabular}{|c|c|c|c|}
\hline \multicolumn{2}{|l|}{ Drug treatment } & \multirow{2}{*}{$\begin{array}{l}I_{50} \\
(\mu M) \\
\text { qRT- } \\
\text { PCR }\end{array}$} & \multirow{2}{*}{$\begin{array}{l}\text { Fold reduction of } \mathrm{IC}_{50} \\
\text { (single/combined) }\end{array}$} \\
\hline & & & \\
\hline \multirow{10}{*}{$\begin{array}{l}\text { Favipiravir- } \\
\text { Niclosamide }\end{array}$} & Favipiravir & 40.49 & \\
\hline & $\begin{array}{l}\text { Favipiravir + Niclosamide } 0.09 \\
\mu \mathrm{M}\end{array}$ & 1.22 & 33.19 \\
\hline & $\begin{array}{l}\text { Favipiravir + Niclosamide } \\
0.045 \mu \mathrm{M}\end{array}$ & 1.31 & 30.91 \\
\hline & $\begin{array}{l}\text { Favipiravir + Niclosamide } \\
0.0225 \mu \mathrm{M}\end{array}$ & 8.51 & 4.76 \\
\hline & $\begin{array}{l}\text { Favipiravir + Niclosamide } \\
0.01125 \mu \mathrm{M}\end{array}$ & 7.86 & 5.15 \\
\hline & Niclosamide & 0.048 & \\
\hline & $\begin{array}{l}\text { Niclosamide + Favipiravir } 80 \\
\mu \mathrm{M}\end{array}$ & 0.002 & 24 \\
\hline & $\begin{array}{l}\text { Niclosamide + Favipiravir } 40 \\
\mu \mathrm{M}\end{array}$ & 0.004 & 12 \\
\hline & $\begin{array}{l}\text { Niclosamide + Favipiravir } 20 \\
\mu \mathrm{M}\end{array}$ & 0.006 & 8 \\
\hline & $\begin{array}{l}\text { Niclosamide + Favipiravir } 10 \\
\mu \mathrm{M}\end{array}$ & 0.014 & 3.428 \\
\hline \multirow{10}{*}{$\begin{array}{l}\text { Favipiravir- } \\
\text { Ivermectin }\end{array}$} & Favipiravir & 40.49 & \\
\hline & Favipiravir + Ivermectin $2.4 \mu \mathrm{M}$ & 0.39 & 103.82 \\
\hline & Favipiravir + Ivermectin $1.2 \mu \mathrm{M}$ & 0.83 & 48.78 \\
\hline & Favipiravir + Ivermectin $0.6 \mu \mathrm{M}$ & 1.09 & 37.15 \\
\hline & Favipiravir + Ivermectin $0.3 \mu \mathrm{M}$ & 6.65 & 6.09 \\
\hline & Ivermectin & 1.24 & \\
\hline & Ivermectin + Favipiravir $80 \mu \mathrm{M}$ & 0.05 & 24.8 \\
\hline & Ivermectin + Favipiravir $40 \mu \mathrm{M}$ & 0.05 & 24.8 \\
\hline & Ivermectin + Favipiravir $20 \mu \mathrm{M}$ & 0.10 & 12.4 \\
\hline & Ivermectin + Favipiravir $10 \mu \mathrm{M}$ & 0.29 & 4.28 \\
\hline
\end{tabular}




\begin{tabular}{|c|c|c|c|}
\hline \multicolumn{2}{|l|}{ Drug treatment } & \multirow{2}{*}{$\begin{array}{l}I_{50} \\
(\mu M) \\
\text { qRT- } \\
\text { PCR }\end{array}$} & \multirow{2}{*}{$\begin{array}{l}\text { Fold reduction of } \mathrm{IC}_{50} \\
\text { (single/combined) }\end{array}$} \\
\hline & & & \\
\hline \multirow{10}{*}{$\begin{array}{l}\text { Favipiravir- } \\
\text { Chloroquine }\end{array}$} & Favipiravir & 40.49 & \\
\hline & $\begin{array}{l}\text { Favipiravir + Chloroquine } 1.7 \\
\mu \mathrm{M}\end{array}$ & 0.50 & 80.98 \\
\hline & $\begin{array}{l}\text { Favipiravir + Chloroquine } 0.85 \\
\mu \mathrm{M}\end{array}$ & 7.50 & 5.40 \\
\hline & $\begin{array}{l}\text { Favipiravir + Chloroquine } 0.425 \\
\mu \mathrm{M}\end{array}$ & 13.01 & 3.11 \\
\hline & $\begin{array}{l}\text { Favipiravir + Chloroquine } \\
0.2125 \mu \mathrm{M}\end{array}$ & 23.48 & 1.72 \\
\hline & Chloroquine & 0.89 & \\
\hline & $\begin{array}{l}\text { Chloroquine + Favipiravir } 80 \\
\mu \mathrm{M}\end{array}$ & 0.02 & 44.5 \\
\hline & $\begin{array}{l}\text { Chloroquine + Favipiravir } 40 \\
\mu \mathrm{M}\end{array}$ & 0.15 & 5.93 \\
\hline & $\begin{array}{l}\text { Chloroquine + Favipiravir } 20 \\
\mu \mathrm{M}\end{array}$ & 0.16 & 5.56 \\
\hline & $\begin{array}{l}\text { Chloroquine + Favipiravir } 10 \\
\mu \mathrm{M}\end{array}$ & 0.60 & 1.48 \\
\hline
\end{tabular}

\section{Evaluation of single drug treatment against SARS-CoV-2 in Calu-3 cells}

Favipiravir-Ivermectin combinations in Vero E6 cells demonstrated the synergy effect using Loewe, ZIP, HSA and Bliss independence reference models. Thus, this combination was selected for further study in the human lung cancer cell line, Calu-3. Firstly, the inhibitory effects of single Favipiravir and Ivermectin treatments were determined using a plaque assay (Fig. 5). The $\mathrm{IC}_{50}$ values of Favipiravir and Ivermectin were $913 \mu \mathrm{M}$ and $0.2 \mu \mathrm{M}$. The effect of drug treatment on cell viability was determined using MTT assay. The $\mathrm{CC}_{50}$ values of Favipiravir and Ivermectin were $>2 \mathrm{mM}$ and $3.09 \mu \mathrm{M}$. Therefore, the SI values of Favipiravir and Ivermectin were $>2.19$ and 15.45 , respectively.

The dose-response curves of a single drug treatment against SARS-CoV-2 are shown; (a) Favipiravir, and (b) Ivermectin. Calu-3 cells were pre-treated with twofold serial dilutions of drug for $1 \mathrm{hr}$. and infected with SARS-CoV-2. The infected cells were maintained in the medium containing serial dilutions of the single drug or $0.5 \%$ DMSO for two days. Virus production was determined using a plaque assay. The doseresponse curves are expressed as the percent inhibitions in relative to the DMSO-treated cell control. The 
effect of drug treatment on cell viability was determined using MTT assay and expressed relative to the DMSO-treated cell control.

\section{Evaluation of Favipiravir-Ivermectin combination treatment against SARS-CoV-2 in Calu-3 cells}

The pairwise combinations of four different concentrations of Favipiravir with 0.4 and $0.2 \mu \mathrm{M}$ Ivermectin induced a strong shift in the dose-response curve of Favipiravir to a comparable level in every pairwise combination. Therefore, we were unable to calculate accurate $\mathrm{IC}_{50}$ values with the least curve fit of these data sets. Thus, the presence of 0.1 and $0.05 \mu \mathrm{M}$ Ivermectin induced a shift in the dose-response curve of Favipiravir, with 1.56 and 1.37-fold reduction of Favipiravir $\mathrm{IC}_{50}$ values, respectively (Fig. 6a, Table 3). Similarly, the presence of Favipiravir also induced a shift in the Ivermectin dose-response curve with $22.22,13.33,2.06$ and 1.33-fold reduction of Ivermectin $I_{50}$ value in the presence of $1.8,0.9,0.45$ and $0.225 \mathrm{mM}$ Favipiravir, respectively (Fig. 6b, Table 3). The dose-response matrix shows the increasing inhibitory effect in relation to the drug concentrations (Fig. 6c). The mean Loewe synergy score of -0.032 accounted for the additive effect between Favipiravir and Ivermectin, with the peak score of 10.614 (Fig. 6d). Moreover, the synergy score calculation using ZIP and Bliss independence models gave values of 3.601, and 3.664, respectively, which indicated the additive effect between Favipiravir and Ivermectin. However, the synergy score of 10.73 was obtained using the HSA model, which indicated a small synergy effect. All 16 pairwise combinations showed no significant cytotoxicity (Fig. 6a, b)

Calu-3 cells were pre-treated for $1 \mathrm{hr}$. with twofold serial dilutions of Favipiravir in the presence of different fixed concentrations of Ivermectin (a) or alternatively, serial dilutions of Ivermectin in the presence of different fixed concentrations of Favipiravir (b). The cells were infected with SARS-CoV-2 at m.o.i. 0.01. After removing the virus inoculum, the cells were further maintained in the medium containing drugs for two days. The virus production was determined using qRT-PCR. The SynergyFinder was used to calculate the synergy score of two-drug combinations from different 16 pairwise combinations. The doseresponse matrix (c) and the synergy map of two-drug combinations treatment (d) are shown. Areas with synergy score less than -10: the interaction between two drugs is likely to be antagonistic; from -10 to 10: the interaction between two drugs is likely to be additive; larger than 10: the interaction between two drugs is likely to be synergistic. 
Table 3

Favipiravir-Ivermectin combination treatments against SARS-CoV-2 in Calu-3 cells

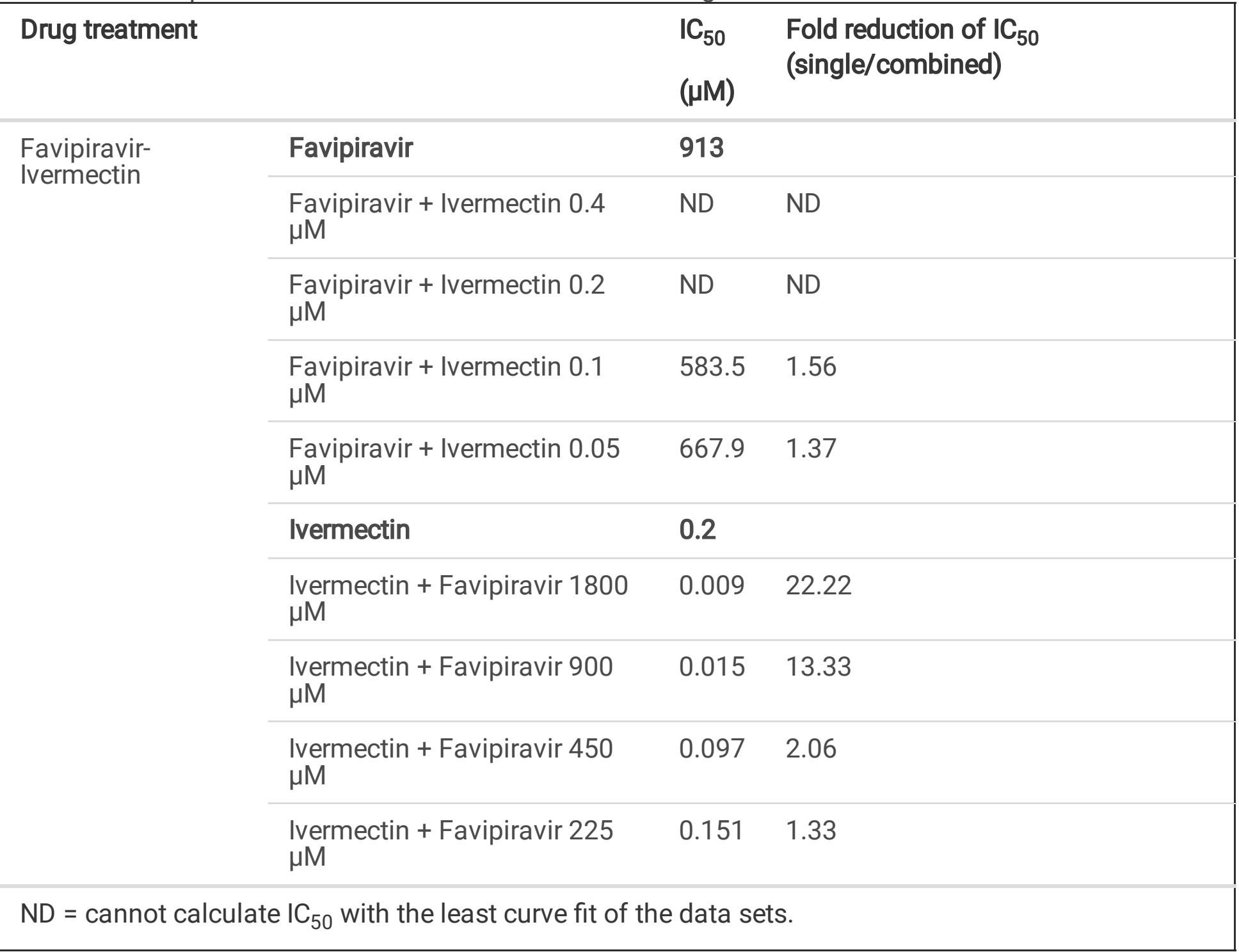

\section{Disscussion}

Favipiravir (T-705; 6-fluoro-3-hydroxy-2-pyrazinecarboxamide) is a pyrazine analog that can prevent RNA elongation by viral RNA-dependent RNA polymerase (RdRp) ${ }^{20}$. Favipiravir (prodrug) receives an intracellular phosphoribosylation to be in an active form (favipiravir ribofuranosyl-5'-triphosphate; Favipiravir-RTP), which is recognized by RdRp and therefore, inhibits the activity of RNA polymerase ${ }^{8}$. Recently, it was shown that Favipiravir also inhibits SARS-CoV-2 by inducing lethal hypermutations ${ }^{21}$. The catalytic domain of RdRp is conserved among several RNA viruses, thus, Favipiravir shows inhibitory effects against a broad range of RNA viruses such as Influenza A viruses ${ }^{10}$, Respiratory syncytial virus 22 , West Nile virus ${ }^{23}$, Zika virus ${ }^{24,25}$ and Ebola virus ${ }^{26}$, etc. Favipiravir has been approved in Japan as an alternative drug for treatment of resistant influenza infection ${ }^{27,28}$. The broad-spectrum antiviral activity of Favipiravir makes it a potentially promising drug for treatment of a wide range of RNA viruses, including recently emerged SARS-CoV-2. However, the anti-SARS-CoV-2 activity of Favipiravir reported by 
previous studies are inconsistent, possibly a result of the differences in experimental models and protocols used. Our results showed anti-SARS-CoV-2 activity of Favipiravir in a high micromolar range ( Vero E6: $I_{50}=40.49 \mu \mathrm{M}$; Calu-3: $I_{50}=913.4 \mu \mathrm{M}$ ), which is in line with the studies by Wang et al. ${ }^{29}$ and Shonnon et al. ${ }^{21}$. They demonstrated a weak inhibitory effect with a $50 \%$ effective concentration $\left(\mathrm{EC}_{50}\right)$ of $61.88 \mu \mathrm{M}$ and $207.1 \mu \mathrm{M}$, respectively, in Vero E6. On the contrary, the study by Jeon et al. and Ohashi et al. showed only a small effect with high-dose Favipiravir ${ }^{30,31}$. Notably, the in vivo studies in a hamster model demonstrated that the anti-SARS-CoV-2 activity of Favipiravir could be achieved with a very high dose ${ }^{32,33}$. Some clinical trials also showed that Favipiravir provided benefit to mild or moderate COVID19 infected patients when taken early ${ }^{34-36}$.

The average maximum plasma concentration of Favipiravir ranges from $362 \mu \mathrm{M}$ to $530 \mu \mathrm{M}$ 37,38, which exceed the drug $\mathrm{IC}_{50}$ obtained from our Vero $\mathrm{E} 6$ model $(40.49 \mu \mathrm{M})$, while, the $\mathrm{IC}_{50}$ obtained using Calu-3 cell was much higher $(913.4 \mu \mathrm{M})$. A previous study demonstrated differences of Favipiravir-RTP levels in different cell lines, higher Favipiravir-RTP levels were observed in Vero, A549, and HEK293T compared to MDCK cells ${ }^{39}$. However, further studies are required to assess the Favipiravir-RTP levels, and the activities of cellular enzymes required for phosphoribosylation in Calu-3 cell and lung cells. Moreover, much higher virus input was used in Calu-3 cells to achieve the stable infection level required for drug treatment in this study. Importantly, the plasma concentration in critical patients was much lower, ranging from $28.2 \mu \mathrm{M}$ to lower than the limit of quantification $(>1 \mu \mathrm{g} / \mathrm{mL}$ or $6.37 \mu \mathrm{M}){ }^{40,41}$, which does not reach the $\mathrm{IC}_{50}$ concentration thereby raising a concern about its efficacy. Therefore, a drug combination appoarch should be used to improve the antiviral activity of Favipiravir. In this study, the repurposed anti-parasitic drugs with broad-spectrum antiviral activity were selected for the two-drug combination treatment including Ivermectin, Niclosamide and Chloroquine.

Ivermectin is a derivative of avermectin (macrocyclic lactones found in Streptomyces avermectinius) and is being used for anti-parasite medication by blocking the transmission of neuronal signals of the parasites. Ivermectin was previously reported to have broad-spectrum antiviral activity in various types of RNA viruses. The proposed mechanism of Ivermectin is that the drug molecule targets the host nuclear transport importin $\alpha / \beta 1$ heterodimer, thereby inhibiting nuclear import of various viral proteins. Several studies demonstrated the antiviral activity of Ivermectin in flaviviruses, including Dengue virus, West Nile virus, and Zika virus, by inhibiting nuclear import of NS5 protein ${ }^{13,42,43}$. In Human Immunodeficiency virus type 1 (HIV-1) and Influenza A viruses, it was shown that Ivermectin inhibited integrase and viral ribonucleoprotein nuclear import, respectively ${ }^{44,45}$. However, the exact mechanism of antiviral activity of Ivermectin has still not been well described.

Our results demonstrated a potent in vitro anti-SARS-CoV-2 activity of Ivermectin in low micromolar range (Vero E6: $I_{50}=1.24 \mu \mathrm{M}$; Calu-3: IC $\mathrm{C}_{50}=0.2 \mu \mathrm{M}$ ). However, many clinical trials showed varying results in COVID-19 treatment ranging from efficacious to no significant benefit ${ }^{15,16,46}$. The maximum plasma concentration of Ivermectin was $0.059 \mu \mathrm{M}$, which was below the $\mathrm{IC}_{50}$ value for anti-SARS-CoV-2 activity. 
However, higher concentrations of Ivermectin were detected in various tissues, including fat, skin and nodular tissues ${ }^{47}$, suggesting a potential of Ivermectin in antiviral therapy. Additionally, a combined phase $2 / 3$ clinical study reported that Ivermectin was safe and reduced the level of plasma nonstructural protein 1 in dengue patients ${ }^{48}$.

To improve the antiviral activity of these drugs, a drug combination approach was used. Favipiravir and Ivermectin showed in vitro synergistic antiviral activity against SARS-CoV-2 in Vero E6 cells. The presence of Ivermectin lowered the Favipiravir $\mathrm{IC}_{50}$. A similar trend was observed for Favipiravir, which also lowered the Ivermectin $\mathrm{IC}_{50}$ to below the maximum plasma concentration. However, in Calu-3 cells, the FavipiravirIvermectin combination only showed an additive effect and the presence of Favipiravir lowered the Ivermectin $\mathrm{IC}_{50}$ to below the maximum plasma concentration. Similarly, the presence of Ivermectin also lowered the Favipiravir $\mathrm{IC}_{50}$. This suggested that a drug combination strategy would help improve antiviral activity. Additionally, the combination of Remdesivir and Ivermectin showed synergism ${ }^{49,50}$. As both Remdesivir and Favipiravir target viral RdRp, their interaction with Ivermectin may represent a similar synergistic mechanism.

Niclosamide is an anthelmintic drug widely used in humans to treat tapeworm infections. The proposed mechanism is inhibiting oxidative phosphorylation and stimulating adenosine triphosphatase activity in the mitochondria of the tapeworm ${ }^{51}$. From several repurposed drug screenings, Niclosamide was identified as a multifunctional drug due to its ability to regulate multiple pathways including mTORC1, STAT3, NF-KB, Notch, NS2B-NS3 interaction, and $\mathrm{pH}^{52,53}$. This made it a potential candidate in the treatment of cancer, bacterial and also virus infections. Many studies demonstrated the antiviral activity of Niclosamide in several viruses such as Middle East respiratory syndrome coronavirus (MERS-CoV) ${ }^{54}$, Dengue virus ${ }^{55}$, Japanese encephalitis virus ${ }^{56}$, hepatitis $C$ virus ${ }^{57}$, Epstein-Barr virus ${ }^{58}$, HIV- ${ }^{59}$ etc. and the recently emerged SARS-CoV-2 ${ }^{19,30}$. In this study, our results showed an anti-SARS-CoV-2 activity of Niclosamide with a low micromolar range (Vero E6: $\left.\mathrm{IC}_{50}=0.048 \mu \mathrm{M}\right)$. However, the exact mechanism of its anti-SARS-CoV-2 is still unclear. Importantly, the Favipiravir-Niclosamide combination in Vero E6 cells demonstrated an additive effect. The drug combination lowered the $\mathrm{IC}_{50}$ of Favipiravir and Niclosamide more than 30 and 10 -fold, respectively.

Chloroquine is an aminoquinoline and is primarily used for malaria treatment. Repurposed drug screening revealed antiviral activity of Chloroquine in diverse types of viruses, including flaviviruses, retroviruses and coronaviruses by inhibiting the $\mathrm{pH}$-dependent steps of viral replication ${ }^{60}$. Many studies and our results showed potent in vitro activity of Chloroquine against SARS-CoV-2 ${ }^{29,61,62}$. The recent study reported that Chloroquine could efficiently block virus infection in Vero and Huh7.5 cells, but not in Calu-3 cells ${ }^{63}$. Vero and Huh7.5 cells require the endosomal acidification during viral entry, while, the entry in Calu-3 cell is pH-independent by using TMPRSS2, a transmembrane serine protease, to cleave the Spike protein extracellularly and bypass the pH-dependent step ${ }^{64,65}$. ). Moreover, in vivo and clinical studies showed that Chloroquine treatment in COVID-19 patients was ineffective ${ }^{66}$. In this study, the Favipiravir- 
Choroquine combination only demonstrated a minimum additive effect. It was previously shown by mathematical modeling that drugs working at the entry step performed poorly in synergism with other drugs ${ }^{67}$. The lack of good synergism with Chloroquine supports with this model. A previous study demonstrated an antagonistic effect of the Hydroxychloroquine and Remdesivir combination against SARS-CoV-2, while Nitazoxanide (that should be similar to Niclosamide) made good synergy with various drugs ${ }^{68}$.

The drug combination approach reported here is used to maximize treatment efficacy. For antiviral treatment, the combination of the antiviral drugs with drugs utilizing different modes of action or acting on cellular targets also helps minimize drug resistance and toxicity ${ }^{69}$. There are several successful drug combinations used in the treatment of HIV-1 and hepatitis $C$ virus ${ }^{70,71}$. From our study, Favipiravir combined with Ivermectin or Niclosamide are the attractive drug combinations to test in clinical trials due to their synergism, relatively good safety profile, and wide availability.

\section{Methods}

\section{Chemicals}

The compounds Niclosamide (N3510, Sigma), Ivermectin (18898, Sigma), and Favipiravir (HY-14768, MCE) were dissolved in $100 \%$ DMSO (Sigma), and Chloroquine (HY-17589, MCE) was dissolved in water and stored at $-80^{\circ} \mathrm{C}$. All drugs were diluted to the working concentrations in a $2 \%$ FBS-MEM for the antiviral experiment in Vero E6 cells or 2\%FBS-DMEM/F12 in Calu-3 cells. The final concentration of DMSO in all experiments was $0.5 \%$.

\section{Cells and viruses}

Vero E6 (CRL-1586, ATCC) cells were cultivated in the minimum essential medium with $1.5 \mathrm{~g} / \mathrm{L}$ sodium bicarbonate, non-essential amino acids, L-glutamine and sodium pyruvate (MEM; 10-009-CV, Corning) supplemented with $10 \%$ heat inactivated FBS $(10 \% \mathrm{FBS}-\mathrm{MEM})$ at $37^{\circ} \mathrm{C}$ with $5 \% \mathrm{CO}_{2}$. Calu-3 cells (HTB-55, ATCC) were cultivated in Dulbecco's Modified Eagle Medium/Nutrient Mixture F-12 (DMEM/F-12; 11320033 , Gibco) supplemented with $10 \%$ heat inactivated FBS (10\%FBS-DMEM/F12) at $37^{\circ} \mathrm{C}$ with $5 \%$ $\mathrm{CO}_{2}$.

SARS-CoV-2 (strain SARS-CoV-2/01/human/Jan2020/Thailand) was previously isolated from nasopharyngeal swabs of a confirmed COVID-19 case in Thailand ${ }^{72}$. The virus was propagated in Vero E6 cells. The supernatants containing virus were harvested by centrifugation to remove cell debris and stored at $-80^{\circ} \mathrm{C}$. The viral titer was determined by plaque assay in Vero E6 cells or $50 \%$ tissue culture infectious dose $\left(\mathrm{TCID}_{50}\right)$ endpoint dilution assay in Calu-3 cells.

\section{SARS-CoV-2 infection}


Vero E6 or Calu-3 cells were seeded in culture plates at a density that allowed $100 \%$ and $70 \%$ confluence, respectively. The culture media were removed and the cells were incubated with $2 \%$ FBS-culture medium containing SARS-CoV-2 at indicated multiplicity of infection (m.o.i.) or 2\%FBS-culture medium as a mock infection for $1 \mathrm{hr}$. at $37^{\circ} \mathrm{C}$ with $5 \% \mathrm{CO}_{2}$. After the viral inoculum was removed, Vero $\mathrm{E} 6$ or Calu-3 cells were further maintained in $2 \%$ FBS-MEM or $2 \%$ FBS-DMEM/F12, respectively, for the indicated time periods.

\section{Cell viability assay}

Vero E6 or Calu-3 cells were seeded in 96-well plates at a density that allowed $100 \%$ and $70 \%$ confluence, respectively. The culture medium was removed, and the cells were treated with the desired concentrations of drugs for $48 \mathrm{hr}$. The cell viability was assessed using MTT dyes (Invitrogen). The viable cells would convert the 3-(4, 5-dimethyl-2-thiazolyl)-2, 5-diphenyl-2H-tetrazolium bromide to MTT formazan. Then DMSO was added to dissolve the precipitates of MTT formazan in the cells, and the absorbance was read at $570 \mathrm{~nm}$. The cells treated with $0.5 \%$ DMSO were used as a cell control. The $50 \%$ cytotoxic concentration $\left(\mathrm{CC}_{50}\right)$ was calculated using non-linear regression analysis.

\section{Drug treatments}

\section{Evaluation of single drug treatment against SARS-CoV-2 in vitro}

Vero E6 or Calu-3 cells were seeded in 96 well-plates at the density of $2.5 \times 10^{4}$ cells/well or $2.0 \times 10^{4}$ cells/well, respectively, before the day of infection. Each drug was twofold serial diluted in 2\%FBS-MEM or $2 \% F B S-D M E M / F 12$. Then the cells were pre-treated with the serial diluted drugs or $0.5 \%$ DMSO as a nodrug control for $1 \mathrm{hr}$. at $37^{\circ} \mathrm{C}$ with $5 \% \mathrm{CO}_{2}$. Subsequently, the cells were incubated with SARS-CoV-2 at m.o.i. 0.01 in Vero E6 cells or 500 TCID $_{50} / 100 \mu$ in Calu-3 cells for 1 hr. For the optimization of SARS-CoV2 infection in Calu-3 cells see supplementary file 1. After that, the viral inoculum was removed. The cells were further maintained in the media containing serial diluted drugs or $0.5 \%$ DMSO for two days. The virus supernatants were collected for titration using a plaque assay and one-step quantitative reversetranscription PCR (qRT-PCR). The half-maximal inhibitory concentration $\left(\mathrm{IC}_{50}\right)$ was calculated from the dose-response curve of drug treatment against SARS-CoV-2 using non-linear regression analysis.

\section{Evaluation of two-drug combinations treatment against SARS-CoV-2 in vitro}

Vero E6 or Calu-3 cells were seeded in 96 well-plates at a density of $2.5 \times 10^{4}$ cells/well or $2.0 \times 10^{4}$ cells/well, respectively. The cells were pre-treated for $1 \mathrm{hr}$. with 16 different pairwise combinations of two drugs. The drug concentrations ranged between $2 x, 1 \times, 0.5 \times$ and $0.25 \times$ of $I_{50}$ values. Subsequently, the cells were infected with SARS-CoV-2 following the same approach used in the single drug experiment. The virus supernatants were collected for titration by qRT-PCR and plaque assay.

\section{Viral quantitation}

\section{Plaque assay}


Vero E6 cells were seeded in 12-well plates at a density of $2.2 \times 10^{5}$ cells/well, which allowed $100 \%$ confluence to be reached within $18 \mathrm{hr}$. The culture medium was removed, and the cells were inoculated with $100 \mu \mathrm{l}$ of 10 -fold serial dilutions of virus supernatants for $1 \mathrm{hr}$. at $37^{\circ} \mathrm{C}$ with $5 \% \mathrm{CO}_{2}$. After that, the virus supernatants were removed, and the cells were overlaid with $1.56 \%$ microcrystalline cellulose (Avicel, RC-591) in 2\%FBS-MEM. The cells were further incubated in the standard condition for three days. The overlaid medium was removed, and the cells were fixed with $10 \%(\mathrm{v} / \mathrm{v})$ formalin in phosphatebuffered saline (PBS) for $2 \mathrm{hr}$. The fixed infected cells were washed in tap water, stained with $1 \%(\mathrm{w} / \mathrm{v})$ crystal violet in $20 \%(\mathrm{v} / \mathrm{v})$ ethanol for $5 \mathrm{~min}$ and washed to remove the excess dyes. The plaques were counted, and the viral titers were calculated in plaque forming units per $\mathrm{ml}(\mathrm{pfu} / \mathrm{ml})$.

\section{$50 \%$ cell culture infectious dose $\left(\mathrm{TCID}_{50}\right)$ endpoint dilution assay}

Vero E6 cells were seeded in 96-well plates at a density of $3 \times 10^{4}$ cells/well. The culture medium was removed, and the cells were incubated with half-log10 serial dilution of the virus stock for $48 \mathrm{hr}$. at $37^{\circ} \mathrm{C}$ with $5 \% \mathrm{CO}_{2}$. After that, the cells were fixed with $1: 1$ methanol/acetone for $30 \mathrm{~min}$ at $4^{\circ} \mathrm{C}$ and the infectivity was detected with an antibody against the SARS-CoV-2 nucleocapsid protein (40143-R001, Sino Biological). The viral $\operatorname{TCID}_{50}$ titers were calculated using the Reed and Muench method ${ }^{73}$.

\section{One-step qRT-PCR for SARS-CoV-2}

The one-step qRT-PCR was used to detect the RNA of SARS-CoV-2 directly from the virus supernatants, without RNA extraction. This assay was validated by comparing the results with viral quantitation using the plaque assay. The procedure was described elsewhere ${ }^{74}$. For the sample preparation, the collected virus supernatants were heat inactivated at $70^{\circ} \mathrm{C}$ for $20 \mathrm{~min}$. Then the samples were diluted 1:10 with DNase/RNase free distilled water. One-step qRT-PCR was performed using the Power SYBR one-step kit (Applied Biosystems) and the LightCycler 480 (Roche, LC480). The one-step RT-PCR master mix was prepared following the kit's instructions for a $10 \mu \mathrm{l}$ reaction volume.

The primers used were CCDC-N-Fw: 5'-GGGGAACTTCTCCTGCTAGAAT-3'and CCDC-N-Rv: 5'CAGACATTTTGCTCTCAAGCTG-3'. Then $5.4 \mu$ of the master mix was mixed with $4.6 \mu$ of the sample in 96-well white PCR plates. RNA of SARS-CoV-2 purified from the virus stock using TRIzol-LS (Invitrogen) was used as a positive control. The samples also included a no-template control (nuclease-free water and the medium of SARS-CoV-2 mock infected cells). The LC480 was run according to the Power SYBR onestep kit's instructions. Briefly, the revere transcription step at $48^{\circ} \mathrm{C}$ for $30 \mathrm{~min}$ and the activation of polymerase at $95^{\circ} \mathrm{C}$ for 10 min was followed by 45 amplification cycles $\left(95^{\circ} \mathrm{C}\right.$ for $15 \mathrm{~s}, 60^{\circ} \mathrm{C}$ for $\left.1 \mathrm{~min}\right)$ and melting curve step to determine the specificity of the PCR product from the melting temperature $\left(T_{m}\right)$ $\left(95^{\circ} \mathrm{C}\right.$ for $30 \mathrm{~s}, 60^{\circ} \mathrm{C}$ for $\left.30 \mathrm{~s}\right)$.

The threshold cycle (Ct) values were calculated from raw fluorescence data using Abs Quant $/ 2^{\text {nd }}$ derivative method. The $T_{m}$ calling analysis was performed to exclude reactions with non-specific 
amplification by comparing with no template control and the product amplified from the positive control. The inhibition of SARS-CoV-2 production in drug treated cells was relative to the cells treated with $0.5 \%$ DMSO.

\section{Evaluation of the combination synergy}

The SynergyFinder web application was used to analyze and visualize the degree of combination synergy. The synergy scores of two-drug combinations were analyzed by comparing the observed drug combination response (percent inhibition) against the expected response, calculated using reference models ${ }^{75}$. The reference models used in this study, including the Loewe additivity (Loewe), Zero Independence Potency (ZIP), Highest Single Agent (HSA), and Bliss independence models ${ }^{76}$. For the synergy score less than -10: the interaction between two drugs is likely to be antagonistic; from -10 to 10 : the interaction between two drugs is likely to be additive; larger than 10: the interaction between two drugs is likely to be synergistic.

\section{Statistical analysis}

All independent experiments were performed in triplicate and the data are shown as mean \pm SD. The $\mathrm{IC}_{50}$ and the $\mathrm{CC}_{50}$ were calculated by non-linear regression analysis using GraphPad Prism 9 (GraphPad Software, Inc., CA). The selective index (SI) was calculated from the ratio between $\mathrm{CC}_{50}$ and $\mathrm{IC}_{50}$.

\section{Declarations}

\section{Acknowledgement}

This study was supported by the Chair Professor Program (P-20-52262), The National Science and Technology Development Agency (NSTDA), Thailand. This study was also partly supported by Faculty of Medicine Siriraj Hospital, Mahidol University, Thailand.

\section{Author contributions}

$\mathrm{KJ}$ performed experiments, analyzed data, wrote the main manuscript text and prepared all figures. $\mathrm{CB}$ prepared performed experiments and edited the manuscript. SM performed virus isolation and prepared virus stock. NP and SB provided cells and drugs. AT and PA provided reagents, methodology and edited the manuscript. P. Auewarakul supervised and conceptualized the study, edited the manuscript, and took funding acquisition. All authors reviewed the manuscript.

\section{Biosafety}

This study was approved by Mahidol University Biosafety Committee (approval no. MU 2020-008).

\section{Competing interests}


The authors declare no competing interests

\section{References}

1 Hurt, A. C. \& Wheatley, A. K. Neutralizing Antibody Therapeutics for COVID-19. Viruses13, 628 (2021).

2 Alam, S. et al. Therapeutic effectiveness and safety of repurposing drugs for the treatment of COVID-19: position standing in 2021. Front Pharmaco/12, 659577, doi:10.3389/fphar.2021.659577 (2021).

3 Ansems, K. et al. Remdesivir for the treatment of COVID-19. Cochrane Database Syst Rev8, Cd014962, doi:10.1002/14651858.Cd014962 (2021).

4 Wang, Y.-Y. et al. Quality of and recommendations for relevant clinical practice guidelines for COVID-19 management: a systematic review and critical appraisal. Front Med8 doi:10.3389/fmed.2021.630765 (2021).

5 Ngo, B. T. et al. The time to offer treatments for COVID-19. Expert Opin Investig Drugs30, 505-518, doi:10.1080/13543784.2021.1901883 (2021).

6 Phougat, N. et al. Combination therapy: the propitious rationale for drug development. Comb Chem High Throughput Screen17, 53-67, doi:10.2174/13862073113166660065 (2014).

7 Furuta, Y. et al. T-705 (favipiravir) and related compounds: Novel broad-spectrum inhibitors of RNA viral infections. Antiviral Res82, 95-102, doi:10.1016/j.antiviral.2009.02.198 (2009).

8 Furuta, Y., Komeno, T. \& Nakamura, T. Favipiravir (T-705), a broad spectrum inhibitor of viral RNA polymerase. Proc Jpn Acad Ser B Phys Biol Sci93, 449-463, doi:10.2183/pjab.93.027 (2017).

9 Wang, Y. et al. The mechanism of action of T-705 as a unique delayed chain terminator on influenza viral polymerase transcription. Biophys Chem277, 106652, doi:https://doi.org/10.1016/j.bpc.2021.106652 (2021).

10 Baranovich, T. et al. T-705 (favipiravir) induces lethal mutagenesis in influenza A H1N1 viruses in vitro. J Viro/87, 3741-3751, doi:10.1128/jvi.02346-12 (2013).

11 Hassanipour, S. et al. The efficacy and safety of Favipiravir in treatment of COVID-19: a systematic review and meta-analysis of clinical trials. Sci Rep11, 11022, doi:10.1038/s41598-021-90551-6 (2021).

12 Department of Medical Services, T. COVID-19 in Thailand, <https://covid19.dms.go.th> (2020).

13 Yang, S. N. Y. et al. The broad spectrum antiviral ivermectin targets the host nuclear transport importin a/ $\beta 1$ heterodimer. Antiviral Res177, 104760, doi:10.1016/j.antiviral.2020.104760 (2020).

14 Caly, L., Druce, J. D., Catton, M. G., Jans, D. A. \& Wagstaff, K. M. The FDA-approved drug ivermectin inhibits the replication of SARS-CoV-2 in vitro. Antiviral Res178, 104787, 
doi:https://doi.org/10.1016/j.antiviral.2020.104787 (2020).

15 Bryant, A. et al. Ivermectin for prevention and treatment of COVID-19 infection: a systematic review, meta-analysis, and trial sequential analysis to inform clinical guidelines. Am J Ther28, e434-e460, doi:10.1097/mjt.0000000000001402 (2021).

16 Popp M, S. M., Metzendorf MI, Gould S, Kranke P, Meybohm P, Skoetz N, Weibel S. Ivermectin for preventing and treating COVID-19. Cochrane Database Syst Rev.28, CD015017, doi:doi:

10.1002/14651858.CD015017.pub2 (2021).

17 Guzzo, C. A. et al. Safety, tolerability, and pharmacokinetics of escalating high doses of ivermectin in healthy adult subjects. J Clin Pharmaco/42, 1122-1133, doi:10.1177/009127002401382731 (2002).

18 Schilling, W. H. et al. The WHO guideline on drugs to prevent COVID-19: small numbers- big conclusions. Wellcome Open Res6, 71, doi:10.12688/wellcomeopenres.16741.1 (2021).

19 Backer, V. et al. A randomized, double-blind, placebo-controlled phase 1 trial of inhaled and intranasal niclosamide: A broad spectrum antiviral candidate for treatment of COVID-19. Lancet Reg Health Eur4, 100084, doi:10.1016/j.lanepe.2021.100084 (2021).

20 Furuta, Y. et al. T-705 (favipiravir) and related compounds: Novel broad-spectrum inhibitors of RNA viral infections. Antiviral Res82, 95-102, doi:10.1016/j.antiviral.2009.02.198 (2009).

21 Shannon, A. et al. Rapid incorporation of Favipiravir by the fast and permissive viral RNA polymerase complex results in SARS-CoV-2 lethal mutagenesis. Nat Commun11, 4682, doi:10.1038/s41467-02018463-z (2020).

22 Jochmans, D. et al. Antiviral activity of Favipiravir (T-705) against a broad range of paramyxoviruses in vitro and against Human Metapneumovirus in hamsters. Antimicrob Agents Chemother60, 4620-4629, doi:10.1128/aac.00709-16 (2016).

23 Escribano-Romero, E., Jiménez de Oya, N., Domingo, E. \& Saiz, J. C. Extinction of West Nile Virus by Favipiravir through Lethal Mutagenesis. Antimicrob Agents Chemother61, doi:10.1128/aac.01400-17 (2017).

24 Kim, J. A., Seong, R. K., Kumar, M. \& Shin, O. S. Favipiravir and Ribavirin Inhibit Replication of Asian and African Strains of Zika Virus in Different Cell Models. Viruses10, doi:10.3390/v10020072 (2018).

25 Pires de Mello, C. P. et al. Clinical regimens of Favipiravir inhibit Zika virus replication in the hollowfiber infection model. Antimicrob Agents Chemother62, doi:10.1128/aac.00967-18 (2018).

26 Guedj, J. et al. Antiviral efficacy of favipiravir against Ebola virus: A translational study in cynomolgus macaques. PLoS Med15, e1002535-e1002535, doi:10.1371/journal.pmed.1002535 (2018). 
27 Goldhill, D. H. et al. Favipiravir-resistant influenza A virus shows potential for transmission. PLoS Pathog17, e1008937, doi:10.1371/journal.ppat.1008937 (2021).

28 Delang, L., Abdelnabi, R. \& Neyts, J. Favipiravir as a potential countermeasure against neglected and emerging RNA viruses. Antiviral Res153, 85-94, doi:10.1016/j.antiviral.2018.03.003 (2018).

29 Wang, M. et al. Remdesivir and chloroquine effectively inhibit the recently emerged novel coronavirus (2019-nCoV) in vitro. Cell Res30, 269-271, doi:10.1038/s41422-020-0282-0 (2020).

30 Jeon, S. et al. Identification of Antiviral Drug Candidates against SARS-CoV-2 from FDA-Approved Drugs. Antimicrob Agents Chemother64, doi:10.1128/aac.00819-20 (2020).

31 Ohashi, H. et al. Potential anti-COVID-19 agents, cepharanthine and nelfinavir, and their usage for combination treatment. iScience24, 102367, doi:doi.org/10.1016/j.isci.2021.102367 (2021).

32 Driouich, J.-S. et al. Favipiravir antiviral efficacy against SARS-CoV-2 in a hamster model. Nat Commun12, 1735, doi:10.1038/s41467-021-21992-w (2021).

33 Kaptein, S. J. F. et al. Favipiravir at high doses has potent antiviral activity in SARS-CoV-2-infected hamsters, whereas hydroxychloroquine lacks activity. Proc Natl Acad Sci U S A117, 26955-26965, doi:10.1073/pnas.2014441117 (2020).

34 Agrawal, U., Raju, R. \& Udwadia, Z. F. Favipiravir: A new and emerging antiviral option in COVID-19. Med J. Armed Forces India76, 370-376, doi:doi.org/10.1016/j.mjafi.2020.08.004 (2020).

35 Cai, Q. et al. Experimental treatment with favipiravir for COVID-19: an open-label control study. Engineering (Beijing)6, 1192-1198, doi:10.1016/j.eng.2020.03.007 (2020).

36 Hassanipour, S. et al. The efficacy and safety of Favipiravir in treatment of COVID-19: a systematic review and meta-analysis of clinical trials. Sci Rep11, 11022, doi:10.1038/s41598-021-90551-6 (2021).

37 Mentré, F. et al. Dose regimen of favipiravir for Ebola virus disease. Lancet Infect Dis15, 150-151, doi:10.1016/S1473-3099(14)71047-3 (2015).

38 Nguyen, T. H. T. et al. Favipiravir pharmacokinetics in Ebola-Infected patients of the JIKI trial reveals concentrations lower than targeted. PLoS Negl Trop Dis11, e0005389-e0005389, doi:10.1371/journal.pntd.0005389 (2017).

39 Huchting, J., Vanderlinden, E., Van Berwaer, R., Meier, C. \& Naesens, L. Cell line-dependent activation and antiviral activity of T-1105, the non-fluorinated analogue of T-705 (favipiravir). Antiviral Res167, 1-5, doi:10.1016/j.antiviral.2019.04.002 (2019).

40 Favié, L. M. et al. Pharmacokinetics of favipiravir during continuous venovenous haemofiltration in a critically ill patient with influenza. Antivir Ther23, 457-461, doi:10.3851/imp3210 (2018). 
41 Irie, K. et al. Pharmacokinetics of Favipiravir in Critically III Patients With COVID-19. Clin Trans/ Sci13, 880-885, doi:10.1111/cts.12827 (2020).

$42 \mathrm{Xu}, \mathrm{T}$.-L. et al. Antivirus effectiveness of ivermectin on dengue virus type 2 in Aedes albopictus. PLOS Negl Trop Dis12, e0006934, doi:10.1371/journal.pntd.0006934 (2018).

43 Kongmanas, K. et al. Immortalized stem cell-derived hepatocyte-like cells: An alternative model for studying dengue pathogenesis and therapy. PLOS Negl Trop Dis14, e0008835, doi:10.1371/journal.pntd.0008835 (2020).

44 Wagstaff, K. M., Sivakumaran, H., Heaton, S. M., Harrich, D. \& Jans, D. A. Ivermectin is a specific inhibitor of importin a/ $\beta$-mediated nuclear import able to inhibit replication of HIV-1 and dengue virus. Biochem J443, 851-856, doi:10.1042/bj20120150 (2012).

$45 \mathrm{Götz}$, V. et al. Influenza A viruses escape from MxA restriction at the expense of efficient nuclear vRNP import. Sci Rep6, 23138-23138, doi:10.1038/srep23138 (2016).

46 Vallejos, J. et al. Ivermectin to prevent hospitalizations in patients with COVID-19 (IVERCOR-COVID19): a structured summary of a study protocol for a randomized controlled trial. Trials21, 965, doi:10.1186/s13063-020-04813-1 (2020).

47 Baraka, O. Z. et al. Ivermectin distribution in the plasma and tissues of patients infected with Onchocerca volvulus. Eur J Clin Pharmaco/50, 407-410, doi:10.1007/s002280050131 (1996).

48 Suputtamongkol, Y. et al. Ivermectin accelerates circulating nonstructural protein 1 (NS1) clearance in adult dengue patients: a combined phase $2 / 3$ randomized double-blinded placebo controlled trial. Clin Infect Dis72, e586-e593, doi:10.1093/cid/ciaa1332 (2021).

49 Tan, Y. L., Tan, K. S. W., Chu, J. J. H. \& Chow, V. T. Combination treatment with Remdesivir and Ivermectin exerts highly synergistic and potent antiviral activity against murine coronavirus infection. Front Cell Infect Microbio/11, doi:10.3389/fcimb.2021.700502 (2021).

50 Jeffreys, L. et al. Remdesivir-Ivermectin combination displays synergistic interaction with improved in vitro antiviral activity against SARS-CoV-2. BioRxiv, 2020.2012.2023.424232, doi:10.1101/2020.12.23.424232 \%J bioRxiv (2020).

51 Kadri, H., Lambourne, O. A. \& Mehellou, Y. Niclosamide, a drug with many Repurposes. Chem Med Chem13, 1088-1091, doi:10.1002/cmdc.201800100 (2018).

52 Xu, J., Shi, P.-Y., Li, H. \& Zhou, J. Broad spectrum antiviral agent Niclosamide and its therapeutic potential. ACS Infect Dis6, 909-915, doi:10.1021/acsinfecdis.0c00052 (2020).

$53 \mathrm{Li}, \mathrm{Y}$. et al. Multi-targeted therapy of cancer by niclosamide: A new application for an old drug. Cancer Lett349, 8-14, doi:10.1016/j.canlet.2014.04.003 (2014). 
54 Gassen, N. C. et al. SKP2 attenuates autophagy through Beclin1-ubiquitination and its inhibition reduces MERS-Coronavirus infection. Nat Commun10, 5770, doi:10.1038/s41467-019-13659-4 (2019).

$55 \mathrm{KaO}, \mathrm{J} .-\mathrm{C}$. et al. The antiparasitic drug niclosamide inhibits dengue virus infection by interfering with endosomal acidification independent of mTOR. PLOS Neg/ Trop Dis12, e0006715-e0006715, doi:10.1371/journal.pntd.0006715 (2018).

56 Fang, J. et al. Identification of three antiviral inhibitors against Japanese encephalitis virus from library of pharmacologically active compounds 1280 . PLoS One8, e78425, doi:10.1371/journal.pone.0078425 (2013).

57 Mazzon, M. et al. Identification of broad-spectrum antiviral compounds by targeting viral entry. Viruses11, 176, doi:10.3390/v11020176 (2019).

58 Huang, L., Yang, M., Yuan, Y., Li, X. \& Kuang, E. Niclosamide inhibits lytic replication of Epstein-Barr virus by disrupting mTOR activation. Antiviral Res138, 68-78, doi:10.1016/j.antiviral.2016.12.002 (2017).

59 Niyomdecha, N., Suptawiwat, O., Boonarkart, C., Jitobaom, K. \& Auewarakul, P. Inhibition of human immunodeficiency virus type 1 by niclosamide through mTORC1 inhibition. Heliyon6, e04050-e04050, doi:10.1016/j.heliyon.2020.e04050 (2020).

60 Kamat, S. \& Kumari, M. Repurposing chloroquine against multiple diseases with special attention to SARS-CoV-2 and associated toxicity. Front Pharmaco/12, 576093-576093, doi:10.3389/fphar.2021.576093 (2021).

61 Vincent, M. J. et al. Chloroquine is a potent inhibitor of SARS coronavirus infection and spread. Virol J2, 69-69, doi:10.1186/1743-422X-2-69 (2005).

62 Musa, I. R. Potential antiviral effect of chloroquine therapy against SARS-CoV-2 infection. Open Access Maced J Med Sci8, 184-191, doi:10.3889/oamjms.2020.4854 (2020).

63 Hoffmann, M. et al. Chloroquine does not inhibit infection of human lung cells with SARS-CoV-2. Nature585, 588-590, doi:10.1038/s41586-020-2575-3 (2020).

64 Dittmar, M. et al. Drug repurposing screens reveal cell-type-specific entry pathways and FDA-approved drugs active against SARS-Cov-2. Cell Rep35, 108959, doi:10.1016/j.celrep.2021.108959 (2021).

65 Hoffmann, M. et al. SARS-CoV-2 Cell Entry Depends on ACE2 and TMPRSS2 and Is Blocked by a Clinically Proven Protease Inhibitor. Cel/181, 271-280.e278, doi:doi.org/10.1016/j.cell.2020.02.052 (2020).

66 Kashour, Z. et al. Efficacy of chloroquine or hydroxychloroquine in COVID-19 patients: a systematic review and meta-analysis. J Antimicrob Chemother76, 30-42, doi:10.1093/jac/dkaa403 (2021). 
67 Melville, K., Rodriguez, T. \& Dobrovolny, H. M. Investigating different mechanisms of action in combination therapy for influenza. Front Pharmaco/9, 1207-1207, doi:10.3389/fphar.2018.01207 (2018).

68 Bobrowski, T. et al. Synergistic and antagonistic drug combinations against SARS-CoV-2. Mol Ther29, 873-885, doi:10.1016/j.ymthe.2020.12.016 (2021).

69 Day, D. \& Siu, L. L. Approaches to modernize the combination drug development paradigm. Genome Med 8, 115-115, doi:10.1186/s13073-016-0369-x (2016).

$70 \mathrm{WHO}$. Updated recommendations on first-line and second-line antiretroviral regimens and postexposure prophylaxis and recommendations on early infant diagnosis of HIV. (2018).

71 AASLD. HCV Guidance: Recommendations for testing, managing, and treating Hepatitis C Virus infection. (2021).

72 Kanjanasirirat, P. et al. High-content screening of Thai medicinal plants reveals Boesenbergia rotunda extract and its component Panduratin A as anti-SARS-CoV-2 agents. Sci Rep10, 19963, doi:10.1038/s41598-020-77003-3 (2020).

73 Reed, L. J. \& Muench, H. A simple method of estimating fifty percent enpoint Am J Epidemio/27, 493497, doi:10.1093/oxfordjournals.aje.a118408 \%J (1938).

74 Ganguly, D. et al. SYBR green one-step qRT-PCR for the detection of SARS-CoV-2 RNA in saliva. 2020.2005.2029.109702, doi:10.1101/2020.05.29.109702\%J bioRxiv (2020).

75 lanevski, A., Giri, A. K. \& Aittokallio, T. SynergyFinder 2.0: visual analytics of multi-drug combination synergies. Nucleic Acids Res48, W488-W493, doi:10.1093/nar/gkaa216 \%J Nucleic Acids Research (2020).

76 Yadav, B., Wennerberg, K., Aittokallio, T. \& Tang, J. Searching for drug synergy in complex doseresponse landscapes using an interaction potency model. Comput Struct Biotechno/13, 504-513, doi:doi.org/10.1016/j.csbj.2015.09.001 (2015).

\section{Figures}


a
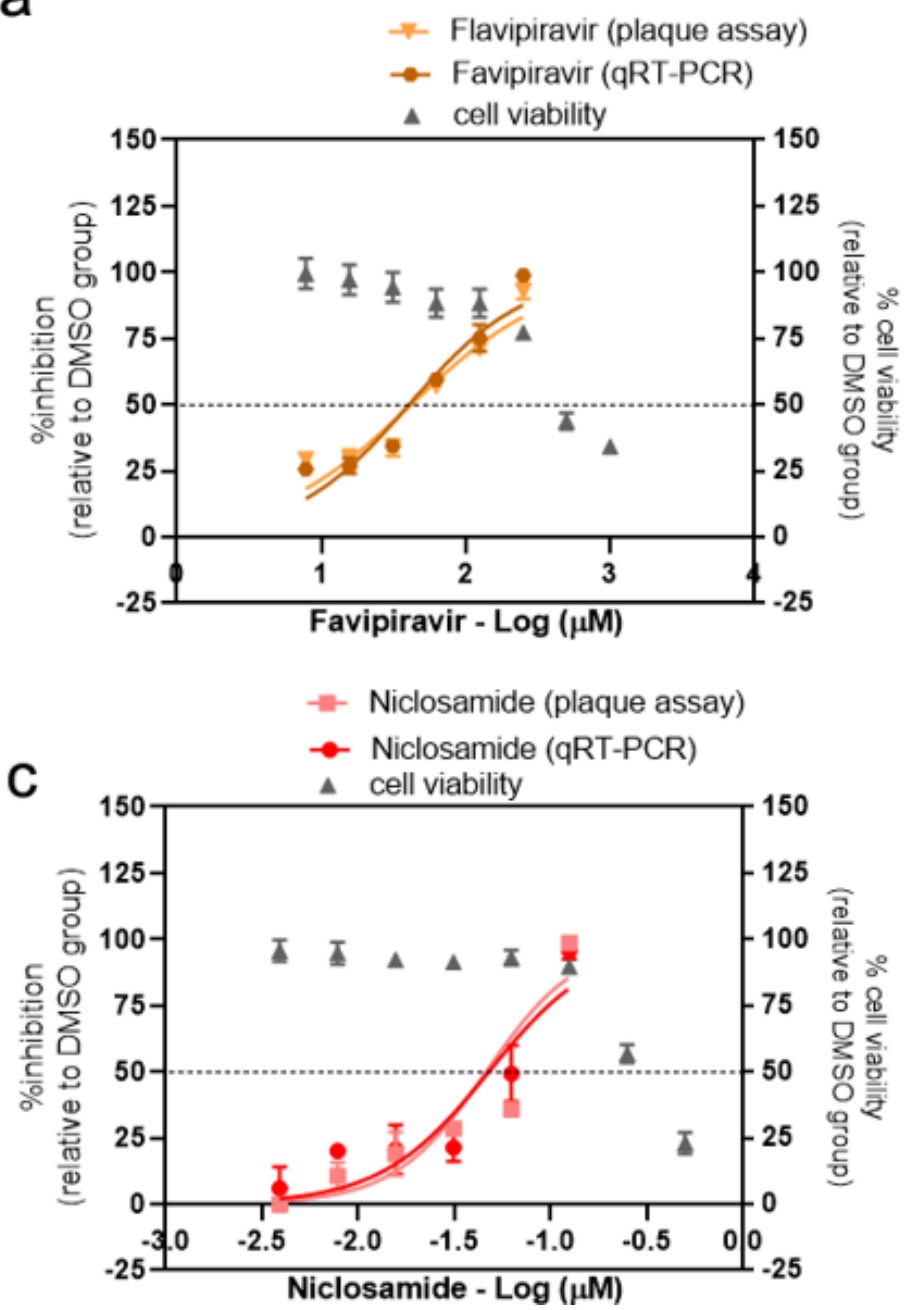
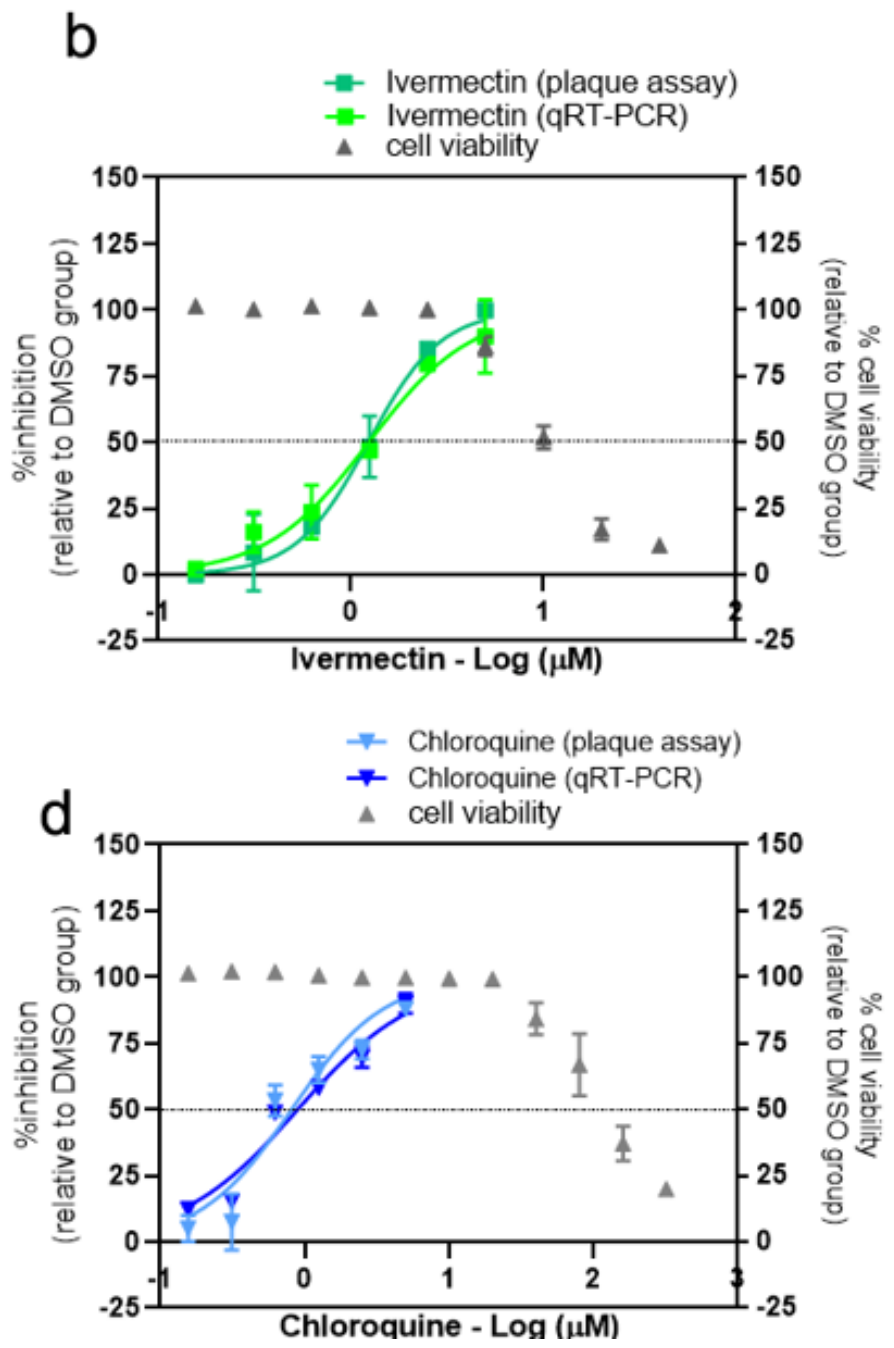

\section{Figure 1}

Evaluation of antiviral activity of drug candidates against SARS-CoV-2 in vitro 
a

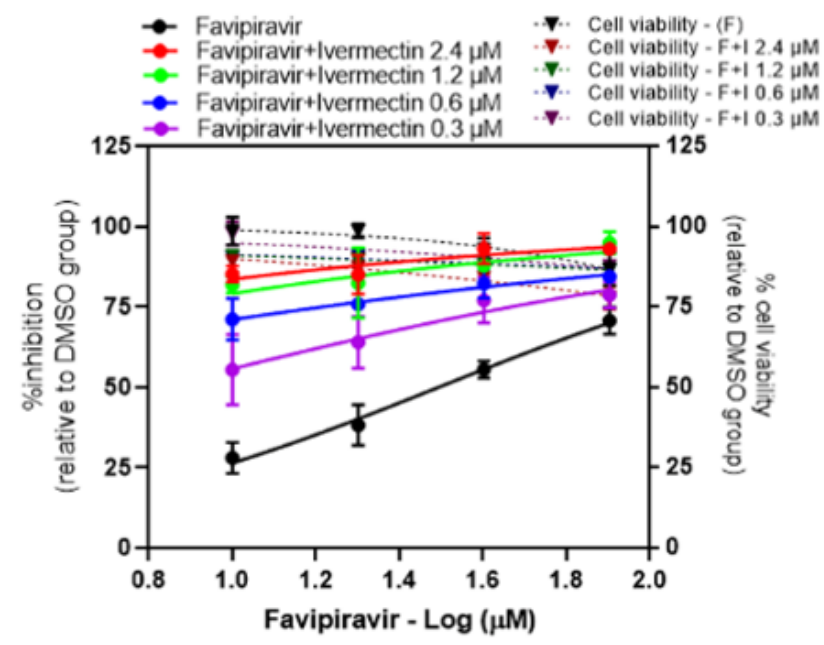

Ivermectin \& Favipiravir

C

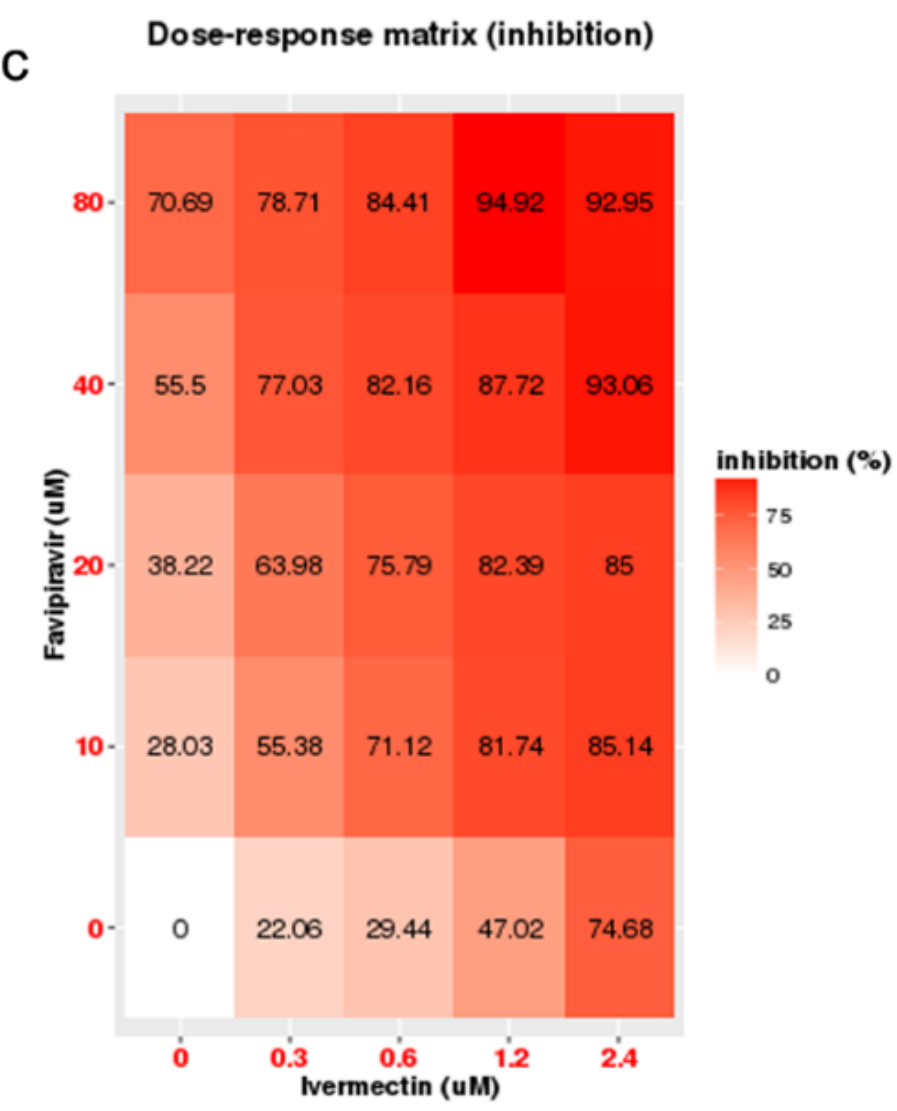

b

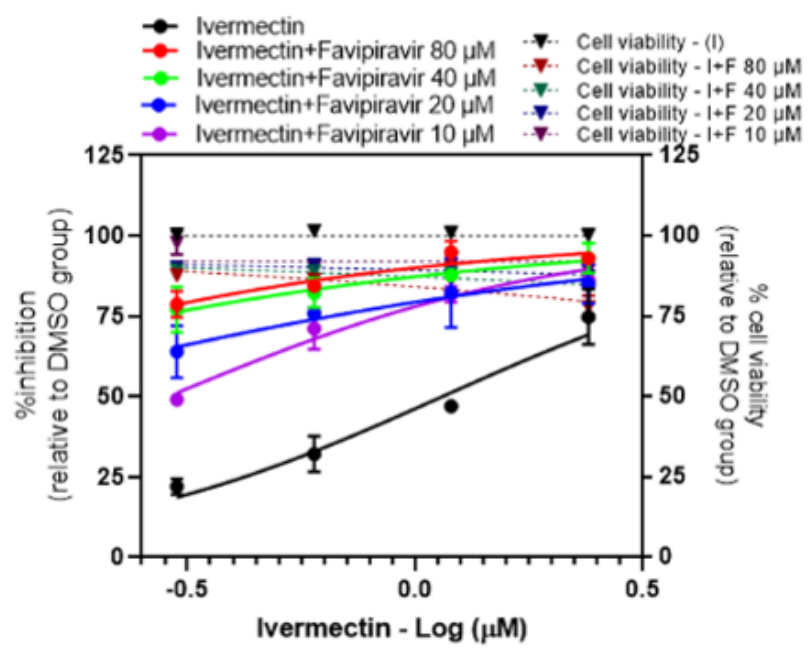

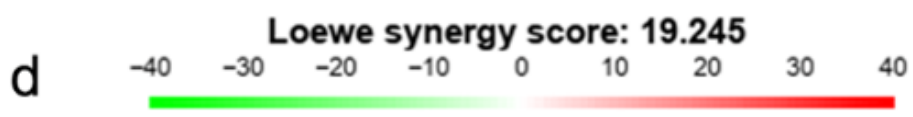

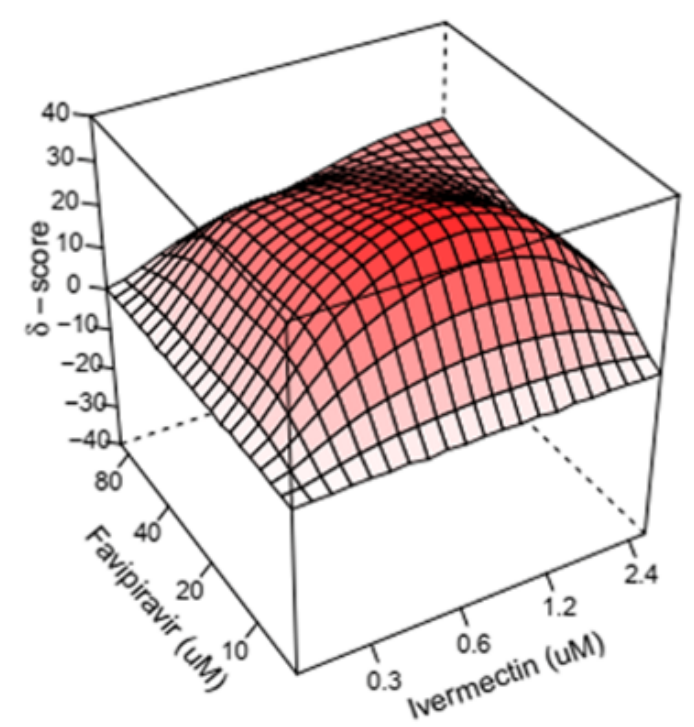

Figure 2

Evaluation of Favipiravir-Ivermectin combination treatments against SARS-CoV-2 in Vero E6 cells 
a

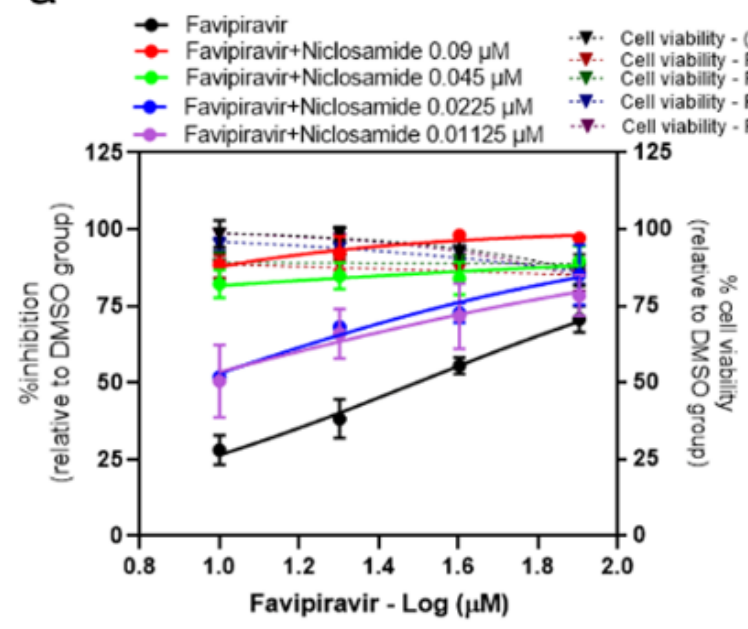

Niclosamide \& Favipiravir

C

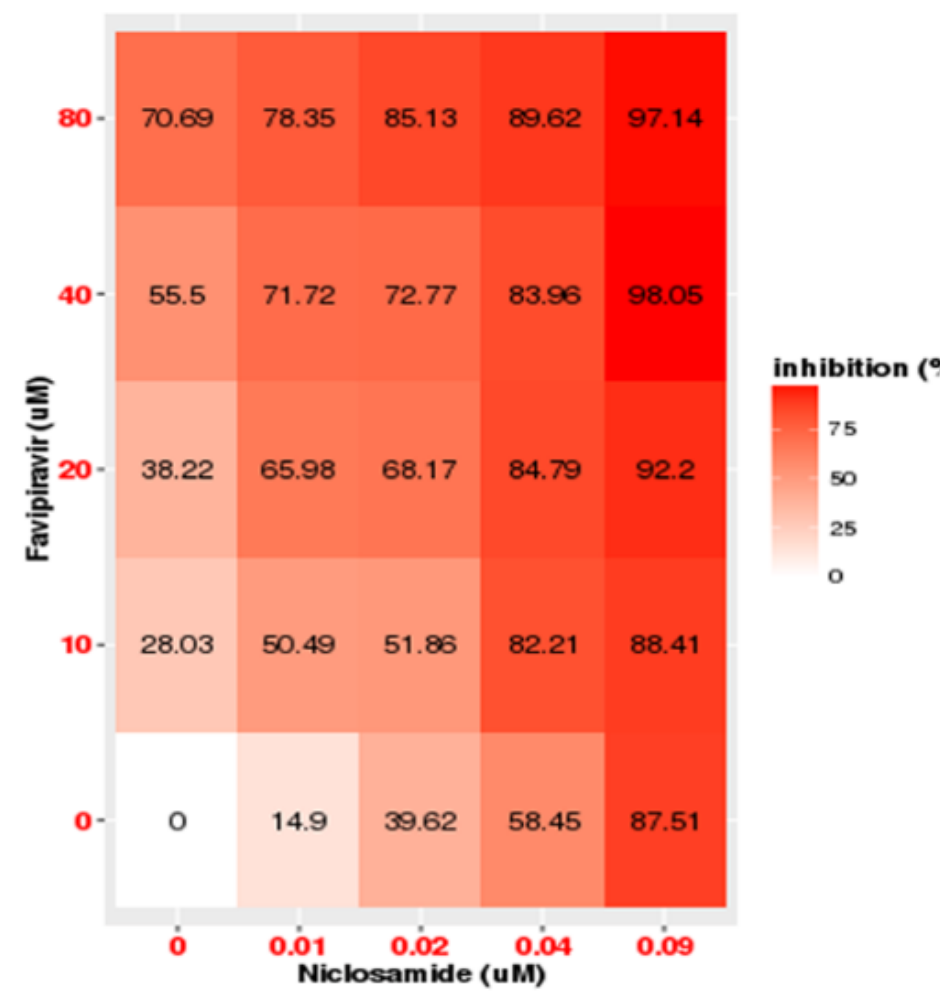

b

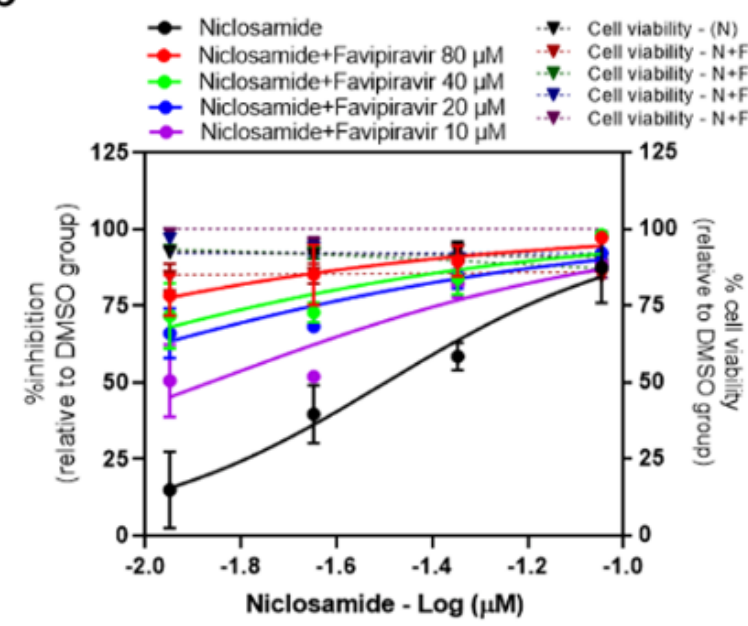

Loewe synergy score: $\mathbf{9 . 6 1}$

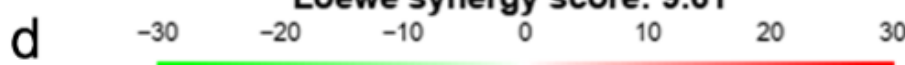

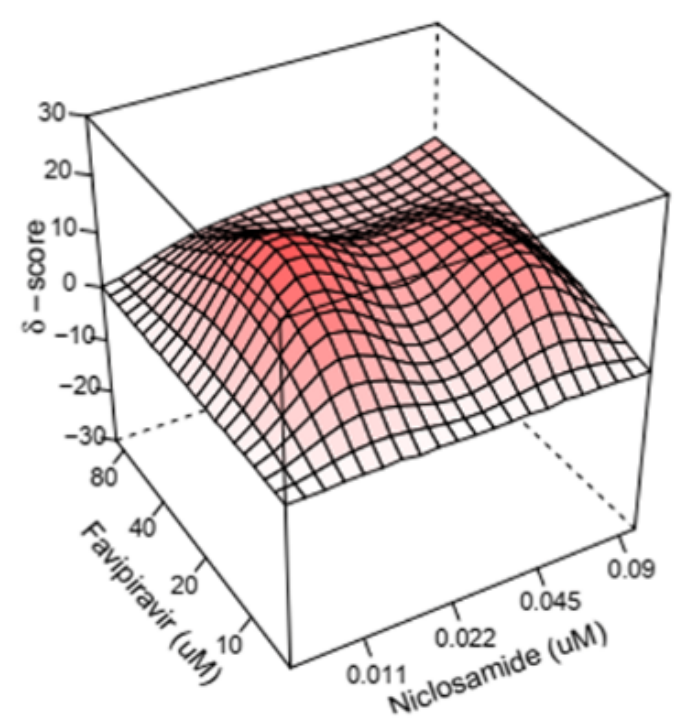

\section{Figure 3}

Evaluation of Favipiravir-Niclosamide combination treatments against SARS-CoV-2 in Vero E6 cells 
a

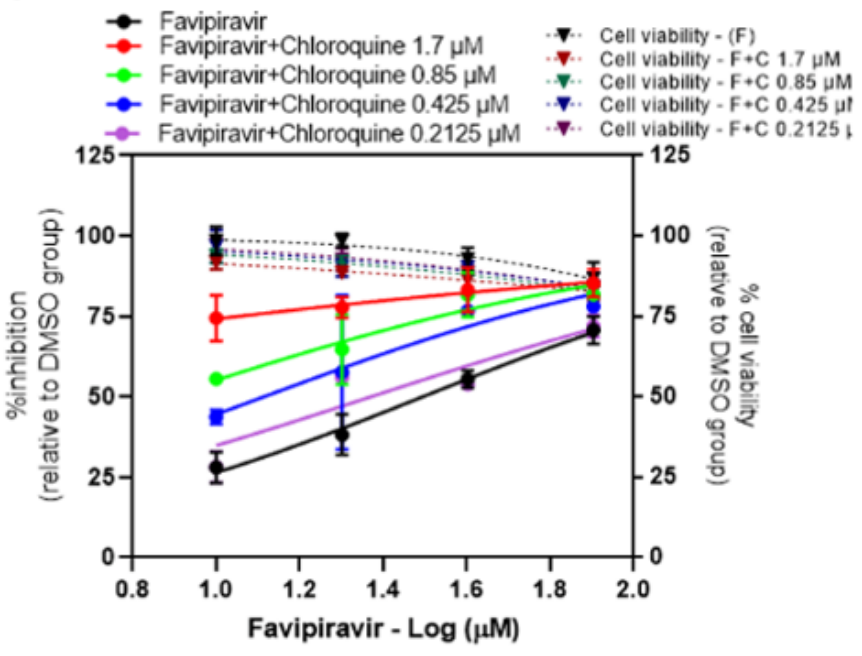

Chloroquine \& Favipiravir

C

\section{Dose-response matrix (inhibition)}

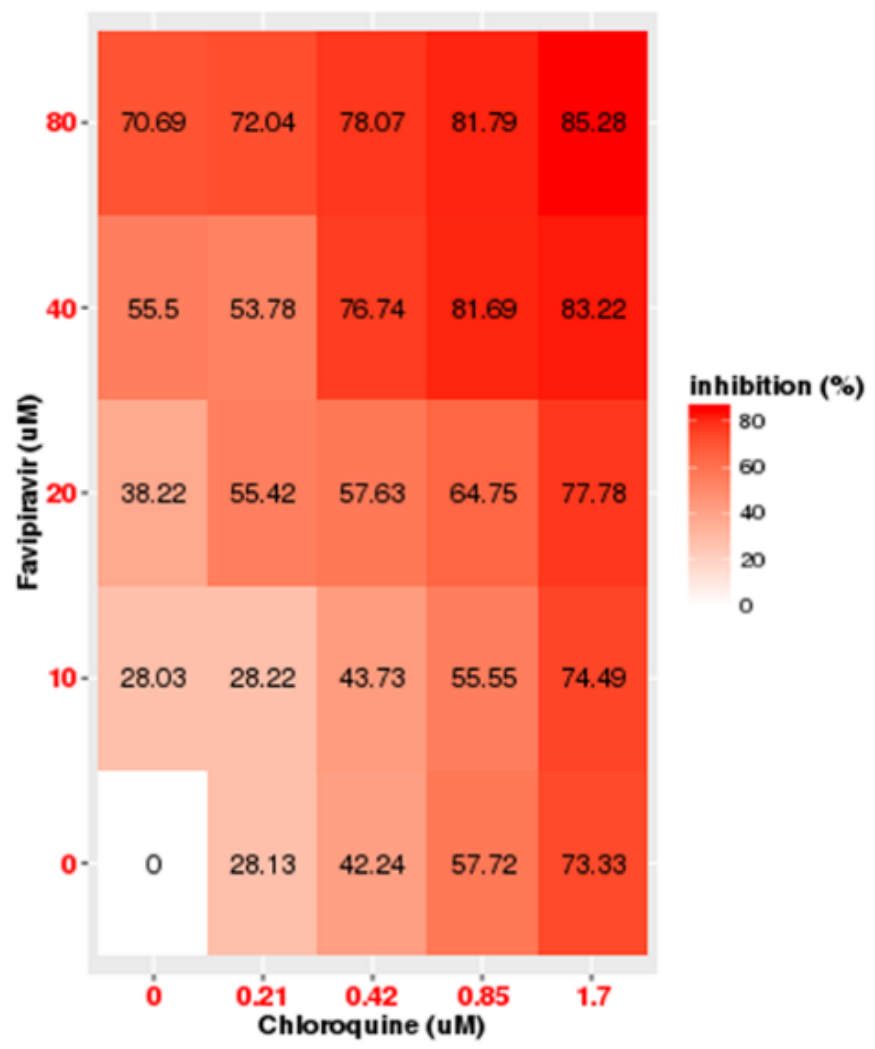

b

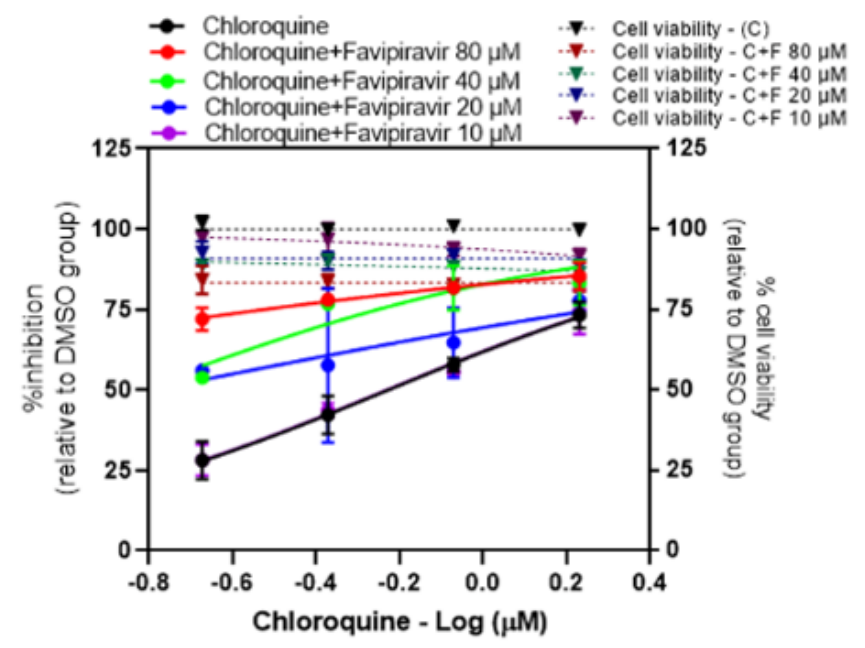

Loewe synergy score: $\mathbf{- 0 . 4 9 4}$

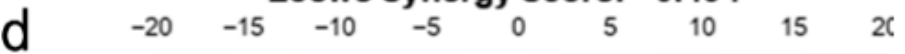

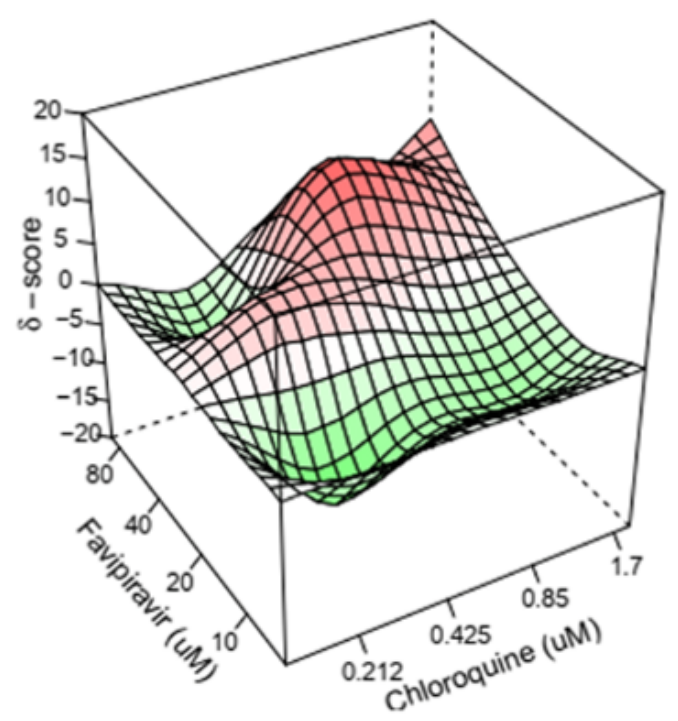

\section{Figure 4}

Evaluation of Favipiravir-Chloroquine combination treatments against SARS-CoV-2 in Vero E6 cells 

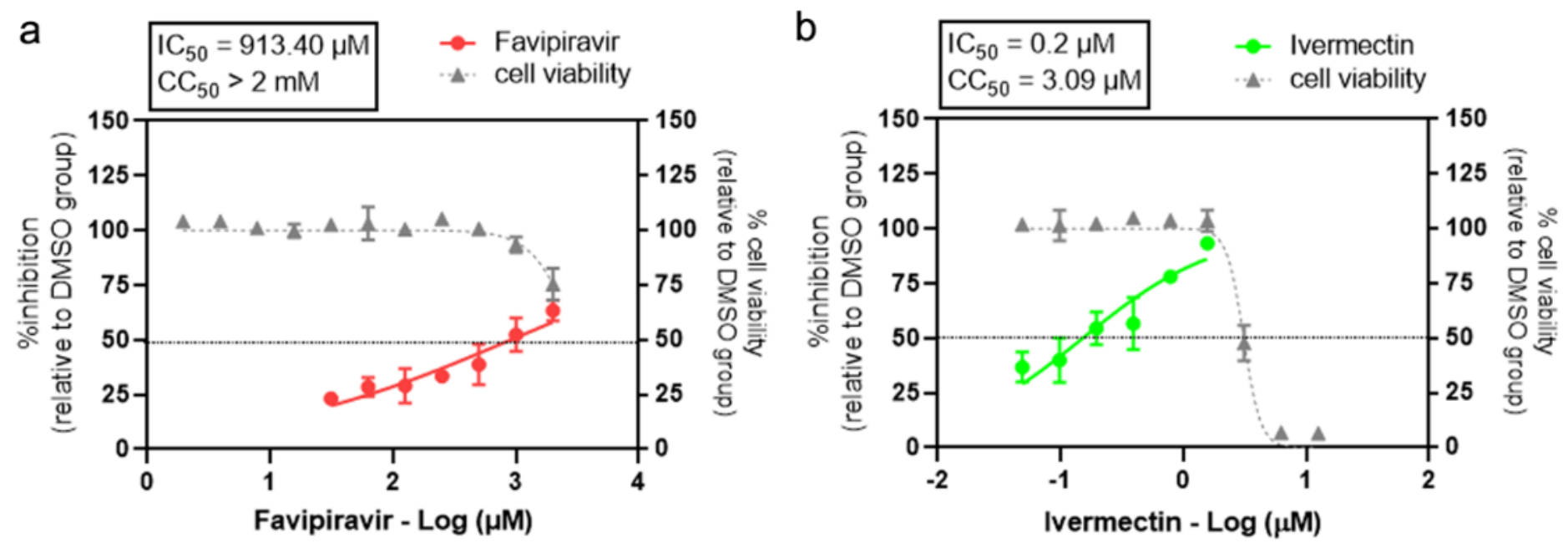

Figure 5

Evaluation of single drug treatment against SARS-CoV-2 in Calu-3 cells 

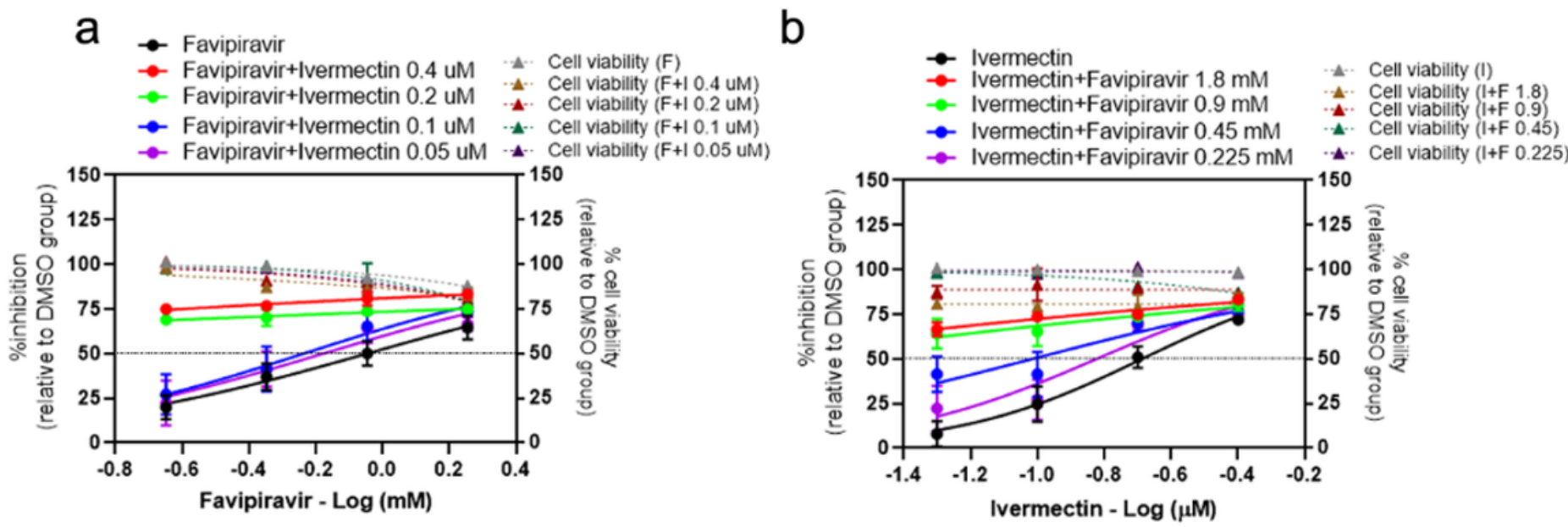

Ivermectin \& Favipiravir
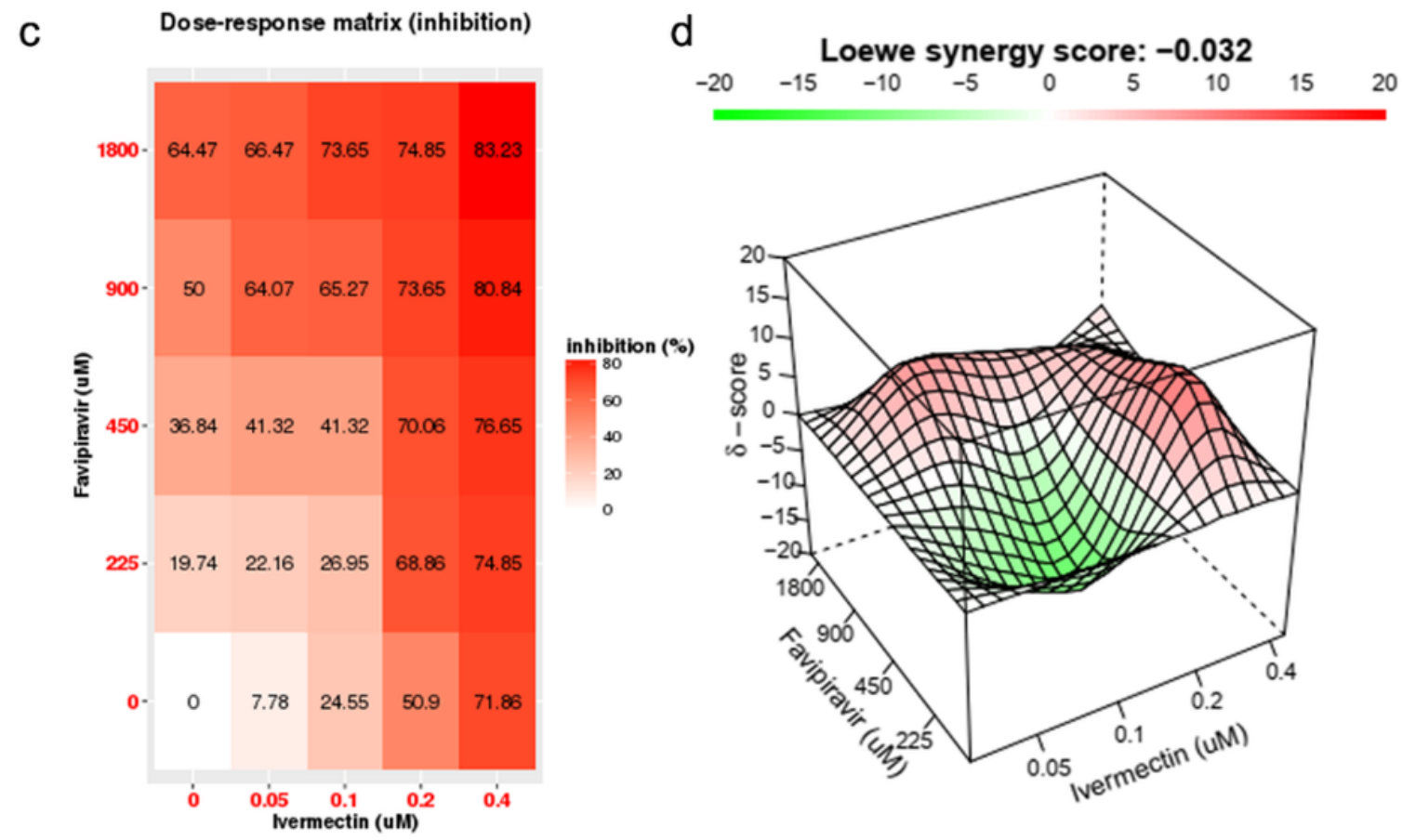

Figure 6

Evaluation of Favipiravir-Ivermectin combination treatments against SARS-CoV-2 in Calu-3 cells

\section{Supplementary Files}

This is a list of supplementary files associated with this preprint. Click to download.

- Supplementaryfile1.docx 